\title{
Mononuclear oxovanadium(IV) Schiff base complex: Synthesis, spectroscopy, electrochemistry, DFT calculation and catalytic activity.
}

Souad DEKAR ${ }^{\mathrm{a}}$, Kamel OUARI*a, Sabrina BENDIA ${ }^{\mathrm{a}}$, Douniazed HANNACHI $^{\mathrm{b}}$ and Jean WEISS

a'Laboratoire d'Electrochimie, d'Ingénierie Moléculaire et de Catalyse Redox (LEIMCR), Faculté de Technologie, Université Sétif-1, 19000, Sétif, Algeria.

bDépartement de Chimie, Faculté des Sciences, Université Sétif-1, 19000, Sétif, Algeria.

${ }^{\circ}$ Laboratoire de Chimie des Ligands à Architecture Contrôlée (CLAC), UMR 7177 CNRS-Université de Strasbourg, 67000 France.

*kamel_ouari@univ-setif.dz

\section{$\underline{\text { Abstract }}$}

A new complex of oxovanadium, VOL has been synthesized from Schiff base ligand obtained by the condensation of $o$-phenylenediamine and 5-bromo-salicylaldehyde. All new compounds have been characterized by ${ }^{1} \mathrm{H}$ NMR, IR spectra, UV-Vis spectroscopy, elemental analysis and mass spectrometry. The molar conductance data revealed that the metal complex is a non-electrolyte. Thermal analysis techniques (TGA/DTA) of the ligand and the complex were performed. The proposed structures for the free ligand and the corresponding vanadium complex were corroborated by the use of geometry optimization and conformational analysis. The solid state structure of complex VOL was fully determined by single crystal X-ray diffraction analysis.

Similar electrochemical behavior for both the ligand and the corresponding complex have been observed by cyclic voltammetry $(\mathrm{CV})$. The complex gave a metal-based one-electron quasireversible redox couple at $606 \mathrm{mV} / \mathrm{SCE}$ corresponding to the $\mathrm{VO}^{\mathrm{IV}} / \mathrm{VO}^{\mathrm{V}}$ redox process which was consistent with the hydrodynamic voltammograms. Additional peaks in the CVs that were growing with the scan rate have been attributed to consecutive one-electron reduction of the ligand. The catalytic activity of the oxovanadium Schiff base complex VOL was tested in the oxidation reaction of cyclohexene. The efficiency of the catalyst was influenced by the nature of the oxidant. The results showed that the complex was highly active and selective for cyclohexenone in optimized conditions.

Keywords: Oxovanadium complex, Spectroscopy, Crystallography, DFT, Cyclic Voltammetry, Oxidation.

\section{Introduction}

In recent decades Schiff bases play an important role in inorganic chemistry as they easily form stable complexes with most transition metal ions [1-3]. The coordination chemistry of 
transition metal-Schiff base complexes has been extraordinary developed in different aspects [4-7] because of their high stability and their important properties in different oxidation states.

Recently much research has been focused on the coordination chemistry of vanadium complexes because of the interesting structural features [8-10], biochemical and pharmacological efficiency as insulinomimetic profile [11], antiparasitic [12] and antitumor activities [13]. In medicinal processes, such as haloperoxidation [15], phosphorylation [16], nitrogen fixation [17], glycogen metabolism [18,19] and insulin mimicking [20,21], spermicidal [22], anti-leukemia [23].

Also, in homogeneous catalysis, vanadium Schiff base complexes formed with chelating ligands involving hetero atoms are found to be used in a variety of systems [14]. Homogeneous catalysts of oxovanadium(IV) complexes induce organic reactions in the oxidation of sulfides and sulfones [24,25], the epoxidation of alkenes [26,27], the hydroxylation of hydrocarbons [28], the oxidation of alcohols to aldehydes and ketones [29,30], phenols [31] and tertiary amines to N-oxides [32]. These studies are indicative that oxovanadium(IV) complexes are potential catalysts to influence the yield and selectivity in chemical transformation [33]. In addition, oxovanadium(IV) complexes, attract considerable attention due to their remarkable catalytic activity and good selectivity for the oxidation of various substrates using $\mathrm{H}_{2} \mathrm{O}_{2}$ as a green oxidant [34], thus responding to the increasing demand for more efficient homogeneous and heterogeneous catalytic systems [35-38].,

The epoxidation of alkenes is one of the most widely studied reactions in organic chemistry since epoxides are key starting materials for a wide variety of products and the catalytic epoxidation of olefins by transition metal complexes is an area of intense research activity [39-40] In the last decades, the synthesis, the structural study and catalytic activity of oxovanadium Schiff base complexes in oxidation of different organic substrates have been described in a great number of publications $[41,42]$. The central metal oxovanadium is surrounded by $\mathrm{N} 2 \mathrm{O} 2$ coordination environment. Recent advances have shown vanadium complexes to be efficient catalysts for the activation of peroxides by virtue of vanadium in terms of stereoselectivity, reactivity and specificity [43]. The ability of these complexes to form metalloperoxo species, which in turn effectively transfer an oxygen atom to reductants with a high degree of selectivity, render them synthetically useful for obtaining valuable molecules.

In order to investigate the catalytic activity of oxovanadium Schiff base complexes as catalysts, we have synthesized in this work a new symmetrical tetradentate Schiff base ligand and its corresponding oxovanadium complex have been characterized by spectroscopic methods. Subsequently, the crystal structure of this new Schiff base complex has been determined by X-ray crystallography. We report hereafter the catalytic epoxidation of cyclohexene in dry solvent using 
hydrogen peroxide and molecular oxygen as oxidants. The electrochemical behavior of the complex has also been investigated.

\section{Experimental}

\subsection{Materials and Measurements}

All chemicals were of reagent grade solvents and all commercially available reagents (Aldrich or Merck) and used without further purification. The syntheses were carried out under inert atmosphere $\left(\mathrm{N}_{2}\right)$ following conventional procedures.

The melting points for the ligand $\mathrm{H}_{2} \mathrm{~L}$ and its complex of $\mathrm{VO}(\mathrm{IV}) \mathrm{L}$ were determined with a Kofler Banc 7779 apparatus and are uncorrected. Infrared spectra were recorded using $\mathrm{KBr}$ pellets on a Shimadzu FTIR IR Affinity-1 spectrophotometer. High-resolution mass spectrum (HRMS) for oxovanadium (IV) complex was acquired via electrospray ionization mass spectrometry (ESI-MS). Electronic spectra were performed on a Shimadzu UV-1800 spectrophotometer using DMF as solvent. Elemental analyses were carried out on an Elementar-Vario EL III CHNSO analyzer. ${ }^{1} \mathrm{H}-$ NMR spectra were recorded on a Bruker Avance $500 \mathrm{MHz}$ spectrometer using DMSO- $\mathrm{d}_{6}$ as solvent and tetramethylsilane (TMS) as internal standard. The molar conductivities of the compounds were carried out on conductivitymeter MeterLab CDM-210 apparatus. Thermogravimetry (TGA) and differential thermoanalysis (DTA) were carried out by using a PL-1500 apparatus, the measurements were performed in nitrogen atmosphere, the heating rate was held at $10{ }^{\circ} \mathrm{C} \mathrm{min}{ }^{-1}$.

The electrochemical properties of the structures were investigated at room temperature in solutions containing Lithium perchlorate $\left(\mathrm{LiClO}_{4}\right), 0.1 \mathrm{M}$, as supporting electrolyte on a glassy carbon (GC) working electrode, the counter electrode was a platinum wire and the reference electrode was a saturated calomel electrode (SCE), the results are given versus SCE. The solvent was DMF with a $10^{-3} \mathrm{M}$ concentration for both the ligand and the complex. The scan rate used in all the voltammograms was of $100 \mathrm{mV} / \mathrm{s}$. All solutions were deoxygenated by passing a stream of prepurified nitrogen into the solution for at least $10 \mathrm{~min}$ prior to recording the voltammograms. Gas chromatography (GC) analyses were carried out on a GC-2014 Shimadzu instrument; it is equipped with a DB5 capillary column of $30 \mathrm{~m}$ length, $0.25 \mathrm{~mm}$ diameter and flame-ionization detector.

\subsection{X-ray crystallography}

Single crystals of VO(IV)L complex were grown by slow layer diffusion of DMSO into a $\mathrm{MeOH}$ solution at room temperature. The crystals were placed in oil and a brown single crystal of dimensions $0.25 \times 0.15 \times 0.12 \mathrm{~mm}^{3}$ was selected, mounted on a glass fiber and placed in a lowtemperature $\mathrm{N}_{2}$ stream. X-ray diffraction data collection was carried out on a Bruker APEX II DUO Kappa-CCD diffractometer equipped with an Oxford Cryosystem liquid $\mathrm{N}_{2}$ device, using Mo Ka 
radiation $(\mathrm{k}=0.71073 \AA$ ) . The crystal-detector distance was $38 \mathrm{~mm}$. The cell parameters were determined (APEX2 software) [44] from reflections taken from tree sets of 12 frames, each at $10 \mathrm{~s}$ exposure. The structure was solved by direct methods using the program SHELXS-97 [45]. The refinement and all further calculations were carried out using SHELXL-97 [46].

The $\mathrm{H}$-atoms were included in calculated positions and treated as riding atoms using SHELXL default parameters. The non-H atoms were refined anisotropically, using weighted fullmatrix least-squares on F2. A semi-empirical absorption correction was applied using SADABS in APEX2 [47]; transmission factors: Tmin/Tmax $=0.580 / 0.746$.

\subsection{General procedure of the oxidation reaction}

In a typical experiment, $15 \mathrm{mmol}$ of the oxovanadium catalyst were dissolved in $15 \mathrm{~mL}$ of DMF, $15 \mathrm{mmol}$ of cyclohexene and $30 \mathrm{mmol}$ of hydrogen peroxide $\left(\mathrm{H}_{2} \mathrm{O}_{2}\right)$ or molecular oxygen $\left(\mathrm{O}_{2}\right)$ were added. With $\mathrm{O}_{2}$, the reaction is carried out under bubbling with a needle introduced into the mixture. The reaction mixture was refluxed while being stirred and the reaction progress was monitored at $1 \mathrm{~h}$ intervals. The optimized reaction time was obtained by following the reaction progress at $1 \mathrm{~h}$ intervals up to $24 \mathrm{~h} ; 6 \mathrm{~h}$ was the optimized reaction time.

In the absence of the complex, no oxidation products were observed. In gas chromatography, the retention times for the starting materials and the products were determined by comparison with authentic samples. The conversion percent $(\%)$ are calculated by the following equation, in which $\mathrm{C}_{\text {initial }}$ and $\mathrm{C}_{\text {final }}$ are initial and final concentration of the substrate, respectively.

$$
\% \text { Conversion }=\left(\frac{\text { Cinitial }- \text { Cfinal }}{\text { Cinitial }}\right) \times 100
$$

\subsection{Synthesis of the ligand}

The tetradentate Schiff base ligand, $\mathbf{H}_{2} \mathbf{L}$, was synthesized according to the literature method [48, 49] by condensing of $1 \mathrm{mmol}(0.108 \mathrm{~g})$ of phenylenediamine with $2 \mathrm{mmol}(0.402 \mathrm{~g})$ of 5 Bromo salicylaldehyde in $15 \mathrm{ml}$ of methanol. The bright orange solution was stirred and heated to reflux for $2 \mathrm{~h}$ under nitrogen atmosphere, scheme 1.

The precipitate was filtered, washed with cold methanol $(3 \times 2 \mathrm{ml})$ and diethyl ether $(3 \times 2 \mathrm{ml})$ and then dried in vacuum over a night. Suitable single crystals for X-ray crystallography were obtained from recrystallization using DMSO/MeOH. Yield: $90 \% ; \mathrm{mp}=234-238{ }^{\circ} \mathrm{C} ; \Lambda_{\mathrm{M}}\left(\Omega^{-1} \mathrm{~cm}^{2}\right.$ $\left.\mathrm{mol}^{-1}\right)=1.47$; IR, KBr pellets, $v \mathrm{~cm}^{-1}: 3457(\mathrm{O}-\mathrm{H}), 1610(\mathrm{C}=\mathrm{N}), 1480(\mathrm{C}=\mathrm{C}), 1274(\mathrm{C}-\mathrm{O})$; UVVis: DMF, $\lambda \mathrm{nm},\left[\varepsilon \mathrm{M}^{-1} \mathrm{~cm}^{-1}\right.$ ]: 267.44 [8738], 343.96 [7095]; ${ }^{1} \mathrm{H} \mathrm{NMR}:\left(\mathrm{CDCl}_{3} \delta \mathrm{ppm}\right): 13.20$ (s, $8.54(\mathrm{~s}, \mathrm{CH}=\mathrm{N}), 6.80-8.00(\mathrm{~m}, \mathrm{ArH}) ;{ }^{13} \mathrm{C} \mathrm{NMR:}\left(\mathrm{CDCl}_{3} \delta \mathrm{ppm}\right): 160.32 \quad(\mathrm{O}-\mathrm{H}), 162.40$ $(\mathrm{CH}=\mathrm{N}), 108-161$ (C-Ar). 


\subsection{Synthesis of the complex}

The title complex, $\mathbf{V O}(\mathbf{I V}) \mathbf{L}$, was prepared in a $10 \mathrm{ml} \mathrm{MeOH}$ by adding dropwise a solution of $0.5 \mathrm{mmol}$ bis (acetylacetonato) oxovanadium in absolute $\mathrm{MeOH}$ to $0.5 \mathrm{mmol}$ of the ligand $\mathbf{H}_{2} \mathbf{L}$. The mixture was refluxed and stirred for $2 \mathrm{~h}$ under nitrogen atmosphere, scheme 1 . The green powder was separated from the solution and purified by washing with cold methanol ( $3 \times 2 \mathrm{ml})$ and diethyl ether $(3 \times 2 \mathrm{ml})$. Suitable single crystals for $\mathrm{X}$-ray crystallography were obtained from recrystallisation using DMSO/MeOH. Yield: 84\%; mp > $260{ }^{\circ} \mathrm{C}$. Analysis calculated for $\mathrm{C}_{20} \mathrm{H}_{12} \mathrm{O}_{2} \mathrm{~N}_{2} \mathrm{Br}_{2} \mathrm{VO}$ : C, 44.65\%; H, 2.24\%; N, $5.20 \%$; found: C, 44.75\%; H, 2.37\%; N, 5.30\%; $\Lambda_{M}$ $\left(\Omega^{-1} \mathrm{~cm}^{2} \mathrm{~mol}^{-1}\right)=3.81$; IR $\left(\mathrm{KBr}\right.$ pellets, $\left.\vee \mathrm{cm}^{-1}\right): 1595(\mathrm{C}=\mathrm{N}), 1428(\mathrm{C}=\mathrm{C}), 1172(\mathrm{C}-\mathrm{O}), 630$ $\left(\mathrm{C}^{-} \mathrm{Br}\right), 968(\mathrm{~V}=\mathrm{O}), 530-555\left(\mathrm{~N}^{-} \mathrm{V}\right), 450-460(\mathrm{O}-\mathrm{V})$. ; UV-Vis: DMF, $\lambda \mathrm{nm},\left[\varepsilon: \mathrm{M}^{-1} \mathrm{~cm}^{-1}\right]: 305.70$ [16054], 322.29 [15800], 414.15 [13000]; ESI/MS: [M++]= 538.76.

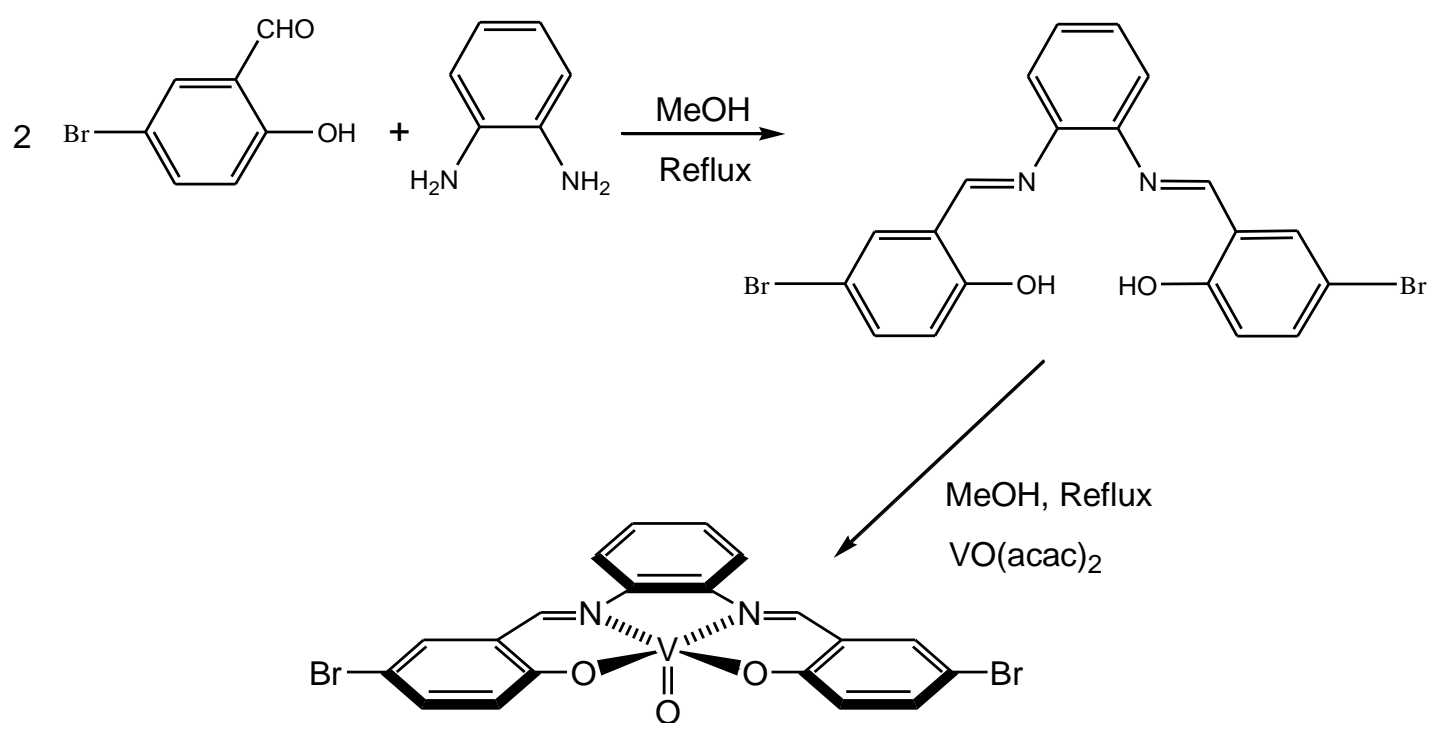

Scheme.1. Synthesis of the ligand $\mathbf{H}_{2} \mathbf{L}$ and the corresponding oxovanadium complex VO(IV)L.

\section{Results and discussion}

The Schiff base $\mathbf{H}_{2} \mathbf{L}$ and oxovanadium complex VO(IV)L are stable at room temperature and are soluble in organic solvents such as DMF, DMSO, $\mathrm{C}_{5} \mathrm{H}_{5} \mathrm{~N}$ and insoluble in inorganic solvents.

\subsection{Elemental analysis}

Elemental analysis data of the oxovanadium complex show good agreement between found and calculated values and fitted well with a 1:1 metal to ligand.

\subsection{Molar conductivity measurements}


The molar conductivity of ligand and its complex were measured in DMF $10^{-3} \mathrm{M}$ as solvent at room temperature, showed a low conductance value, 1.47 and $3.81 \mathrm{ohm}^{-1} \mathrm{~cm}^{2} \mathrm{~mol}^{-1}$, respectively, suggest a non electrolytic nature and there is no counter ion present outside the coordination sphere $[50,51]$.

\subsection{Electronic spectral studies}

The electronic spectral bands of the Schiff base ligand $\mathbf{H}_{2} \mathbf{L}$ and its corresponding complex VO(IV)L are presented in Table.1.

In the 200 to $800 \mathrm{~nm}$ wavelength range, the Schiff base ligand exhibits two bands at 267 and $344 \mathrm{~nm}$. The first band is attributed to the $\pi-\pi^{*}$ transitions in the diamine aromatic backbone. The second one is due to $n-\pi^{*}$ transition of the azomethine group [52, 53].

In the complex, the three bands localized at 306 and $322 \mathrm{~nm}$ are assigned to the intra-ligand $\pi-\pi^{*}$ and $n-\pi^{*}$ and $414 \mathrm{~nm}$ due to LMCT transitions $[54,55]$. The $\mathrm{d}-\mathrm{d}$ transitions were not observed for the $\mathbf{V O}(\mathbf{I V}) \mathbf{L}$ complex.

Table.1. Electronic spectra of the $\mathrm{H}_{2} \mathrm{~L}$ and $\mathrm{VO}(\mathrm{IV}) \mathrm{L}$

\begin{tabular}{lccc}
\hline \multirow{2}{*}{ Compounds } & \multicolumn{2}{c}{ UV-Vis } & \multirow{2}{*}{ Assignement } \\
\cline { 2 - 3 } & $\lambda \max (\mathbf{n m})$ & $\left(\varepsilon, \mathbf{M}^{-1} \mathrm{~cm}^{-1}\right)$ & \\
\hline \multirow{2}{*}{$\mathrm{H}_{2} \mathrm{~L}$} & 267 & $(\mathbf{8 7 3 8})$ & $\pi-\pi^{*}$ \\
& 344 & $(7095)$ & $\mathbf{n}-\pi^{*}$ \\
\hline \multirow{2}{*}{ VOL } & 306 & $(16054)$ & $\pi-\pi^{*}$ \\
& 322 & $(15800)$ & $\mathbf{n}-\pi^{*}$ \\
& 414 & $(13000)$ & LMCT \\
\hline
\end{tabular}

\subsection{Infrared spectra}

The IR spectra of the free Schiff base ligand and the complex exhibit several bands in 400$4000 \mathrm{~cm}^{-1}$ region.

The IR spectrum of the ligand, a sharp $\mathrm{C}=\mathrm{N}$ band was observed at $1621 \mathrm{~cm}^{-1}$ [56]. The ligand displays intense bands at 3457 and $1274 \mathrm{~cm}^{-1}$ which are assigned to $v(\mathrm{O}-\mathrm{H})$ and $v(\mathrm{C}-\mathrm{O})$ stretching vibrations of the phenolic moieties. Bands appearing in the range $1473-1561 \mathrm{~cm}^{-1}$ are related to the aromatic $\mathrm{C}=\mathrm{C}$ vibrations. Additionally, the band observed at $630 \mathrm{~cm}^{-1}$ is assigned to the $\mathrm{C}-\mathrm{Br}$ vibration [57].

In the spectrum of the complex, the vibration bands observed in the Schiff bases were decreased in intensity and shifted towards a lower frequency for the $\mathrm{C}=\mathrm{N}$ band, $1604 \mathrm{~cm}^{-1}[58,59]$, the frequency of the $\mathrm{C}-\mathrm{O}$ band is shifted to a higher value, $1293 \mathrm{~cm}^{-1}$, indicating that the nitrogen 
atom of the azomethine group and the oxygen of the phenolic moiety are coordinated to the metal ion [60]. The oxovanadium complex shows a band at $968 \mathrm{~cm}^{-1}$ attributed to $\mathrm{V}=\mathrm{O}$ frequency [61].

\subsection{NMR spectroscopy}

The chemical shifts of the different types of protons in the ${ }^{1} \mathrm{H}$ NMR spectra of the $\mathbf{H}_{2} \mathbf{L}$ ligand was reported in Table 2.

The structure of the synthesized ligand is given by the following scheme:

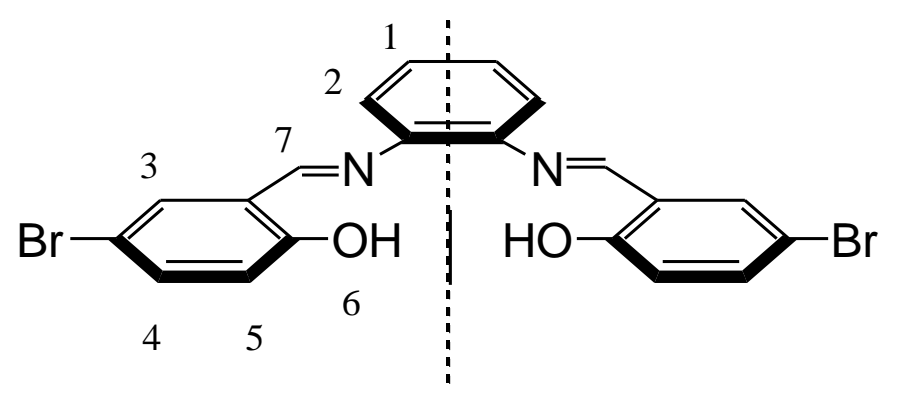

$\mathbf{H}_{2} \mathbf{L}$

Table.2. Chemical shifts (in ppm) of the proton of the ligand in $\mathrm{CDCl}_{3}$

\begin{tabular}{cccc}
\hline Compound & $\mathrm{H}_{6}(\mathrm{OH})$ & $\mathrm{H}_{7}(\mathrm{CH}=\mathrm{N})$ & $\mathrm{H}_{1-5}(\mathrm{Ar})$ \\
\hline $\mathrm{H}_{2} \mathrm{~L}$ & 13.20 & 8.54 & $6.80-8.00$ \\
\hline
\end{tabular}

The ${ }^{1} \mathrm{H}$ NMR spectra of Schiff bases shows signals in conformity with the structure. The peak observed at $13.20 \mathrm{ppm}$ in these Schiff bases was assignable to the $\mathrm{O}-\mathrm{H}$ of the bromophenol form. The azomethine proton appears at $8.54 \mathrm{ppm}$. Multiplet signal, due to the aromatic protons, are observed in the range $6.88-8.00 \mathrm{ppm}[49]$.

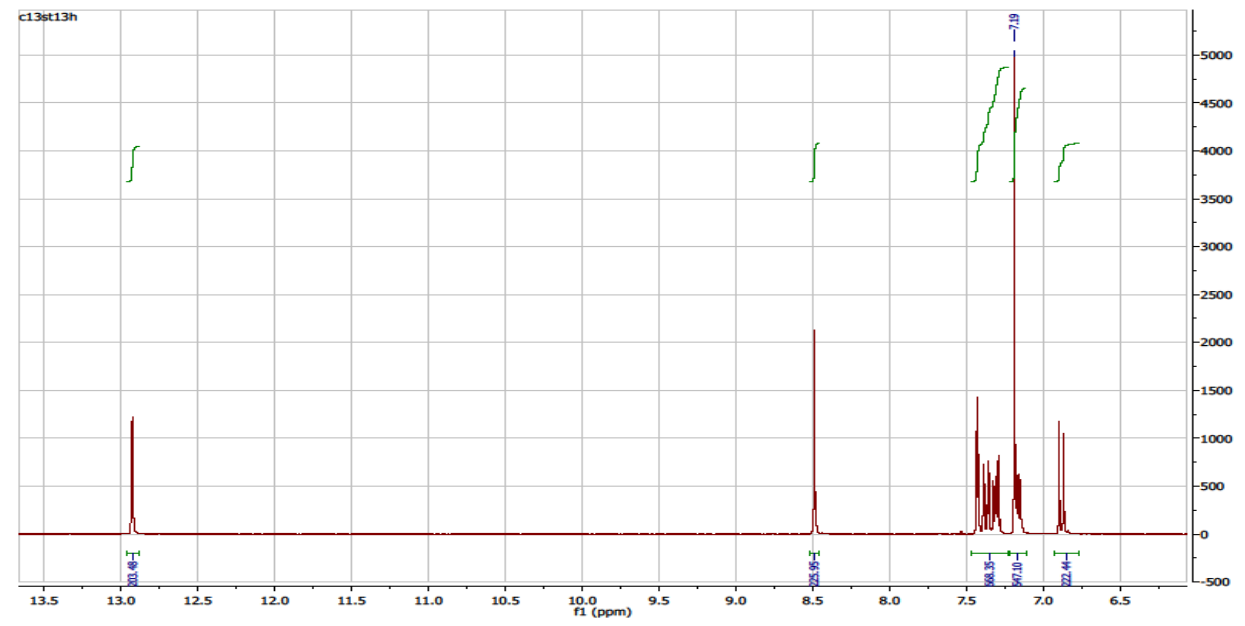

Fig.1. ${ }^{1} \mathrm{H}$ NMR spectrum of Schiff base ligand $\left(\mathrm{H}_{2} \mathrm{~L}\right)$ in $\mathrm{CDCl}_{3}$.

\subsection{Mass spectrometry}


The figure.2. below illustrates the mass spectrum of the complex $\mathbf{V O}(\mathbf{I V}) \mathbf{L}$. The peak appearing at $\mathrm{m} / \mathrm{z}=538.76$ is the molecular peak $\left[\mathrm{M}^{++}\right]$.

The dibrominated complex mass spectrum presents its expected molecular peak cluster, due to the relative abundance of the bromine atome isotopes $[62,63]$.

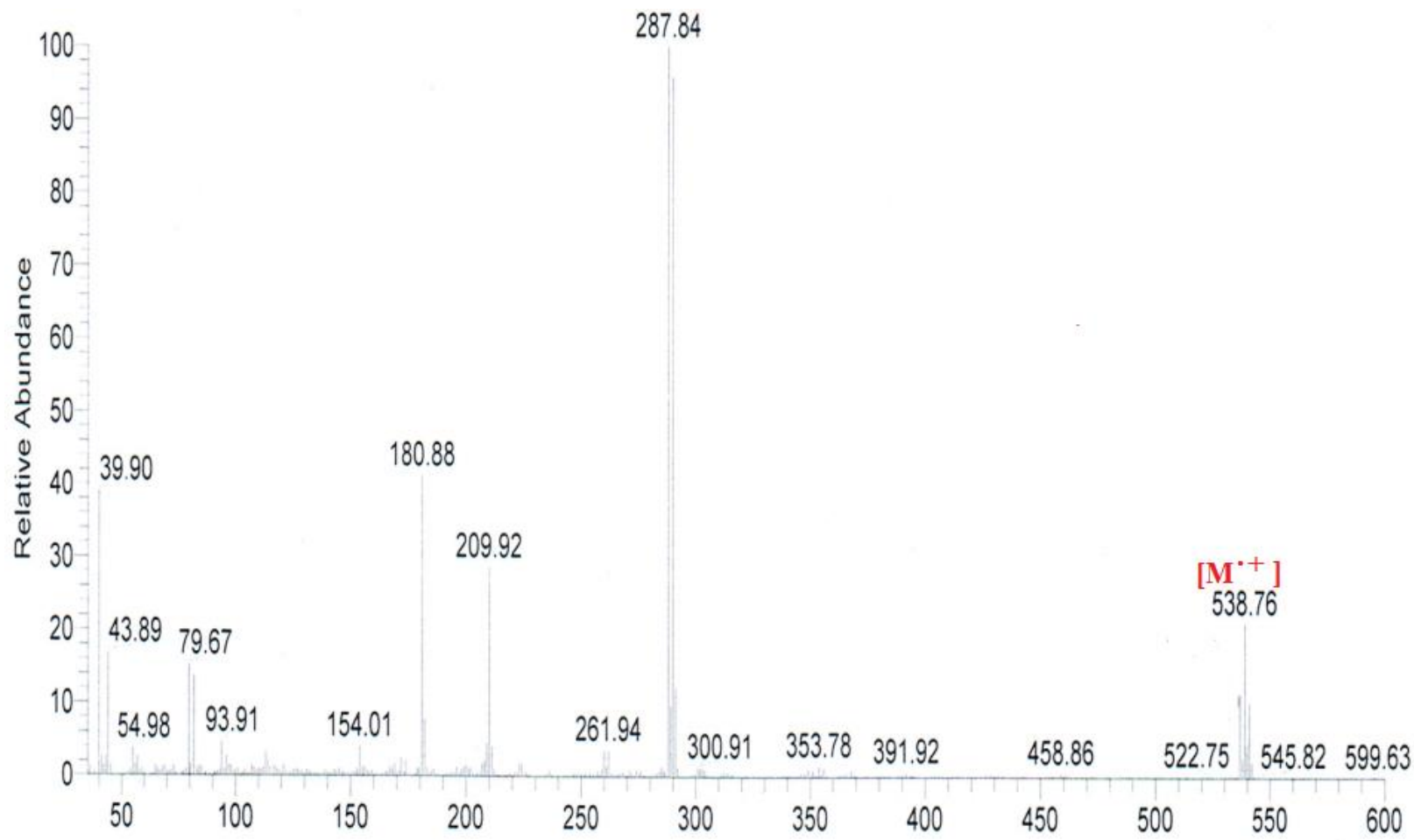

Fig.2. The mass spectrum of oxovanadium complex VO(IV)L.

\subsection{X-ray crystal structure}

An ORTEP view of VO(IV)L with the atom-numbering scheme is presented in Fig.3. Table 3 shows crystal data, data collection and structure refinement parameters. Most relevant bond lengths and angles are given in Table.4.

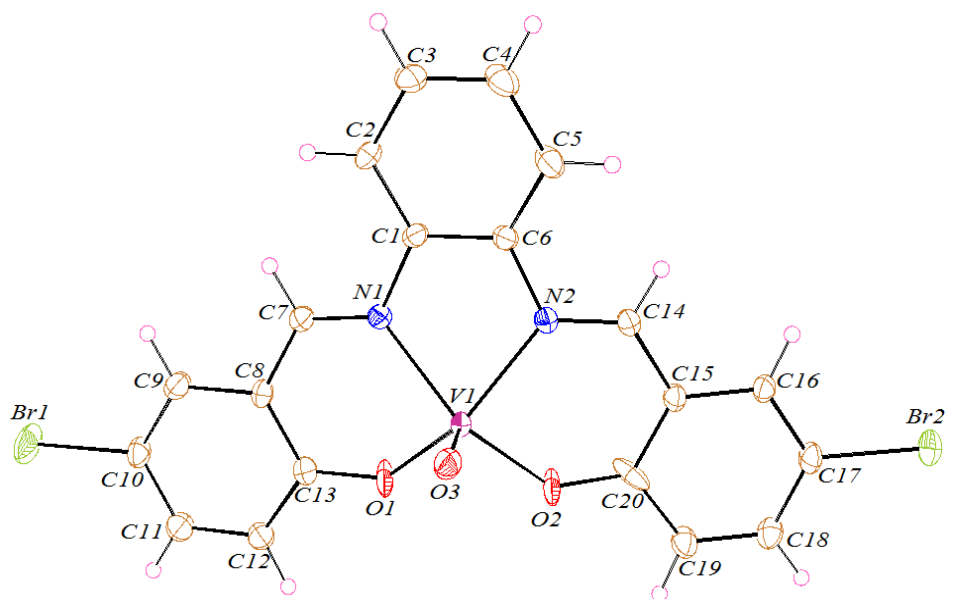

Fig.3. The molecular structure of the oxovanadium complex. Thermal ellipsoids are drawn at $50 \%$ probability 
Table.3. Crystallographic and refinement data for VO(IV)L complex.

\begin{tabular}{|c|c|}
\hline Compound & VO(IV)L \\
\hline Molecular formula moiety & $\mathrm{C}_{20} \mathrm{H}_{12} \mathrm{Br}_{2} \mathrm{~N}_{2} \mathrm{O}_{3} \mathrm{~V}$ \\
\hline Molecular weight & $173(2)$ \\
\hline Temperature (K) & Mo-K $\quad(0.71073 \AA)$ \\
\hline Radiation & Monoclinic \\
\hline Crystal system & $P 2{ }_{1} / c$ \\
\hline Space group & $11.0545(8)$ \\
\hline$a / \AA$ & $18.1170(12)$ \\
\hline$b / \AA$ & $9.6547(7)$ \\
\hline$c / \AA$ & 90.00 \\
\hline alpha $^{\circ}$ & $108.581(2)$ \\
\hline Beta $^{\circ}$ & 90.00 \\
\hline $\operatorname{gamma}^{\circ}$ & $1832.8(2)$ \\
\hline $\mathrm{V} / \AA^{3}$ & 4 \\
\hline $\mathrm{Z}$ & 1.954 \\
\hline $\mathrm{D}_{\text {calc }}\left(\mathrm{mg} \mathrm{m}^{-3}\right)$ & $0.25 \times 0.15 \times 0.12$ \\
\hline Crystal size $\left(\mathrm{mm}^{3}\right)$ & Prism \\
\hline Crystal description & Brown \\
\hline Crystal colour & 4.927 \\
\hline Absorption coefficient $\left(\mathrm{mm}^{-1}\right)$ & 1052 \\
\hline$F\left(\begin{array}{lll}0 & 0 & 0\end{array}\right)$ & $28978 / 3856\left[\mathrm{R}_{\text {int }}=0.044\right]$ \\
\hline Reflections collected/unique & $-15,15 ;-24,24 ;-13,8$ \\
\hline Range/indices $(h, k, l)$ & $1.944-29.022$ \\
\hline Tetalimit $_{1}$ & 3856 \\
\hline No. of observed data, $I>2 \operatorname{Sigma}(I)$ & 247 \\
\hline No. of variables & 0 \\
\hline No. of restraints & 1.158 \\
\hline Goodness of fit on $F^{2}$ & 4.02 and -1.77 \\
\hline Largest diff. Peak and hole $\left(\mathrm{e} \AA^{-3}\right)$ & $0.0710,0.1724$ \\
\hline$R_{1}, w R_{2}[I \geq 2 \operatorname{Sigma}(I)]^{\mathrm{a}}$ & $0.0901,0.1815$ \\
\hline$R_{1}, w R_{2}(\text { all data })^{\mathrm{a}}$ & \\
\hline
\end{tabular}

The crystal structure shows the presence of one molecule of mononuclear complex in the asymmetric unit. The VO(IV)L crystallizes in the monoclinic system with space group $P 21 / c$ and the cell dimensions $\mathrm{a}=11.0545$ (8) ; b = 18.1170 (12) ; $\mathrm{c}=9.6547$ (7) $\AA$; $\mathrm{a}=\tilde{\mathrm{a}}=90^{\circ} ; \mathrm{a}=108.581$ (2). The oxovanadium atom in this complex is coordinated by the two nitrogen and two oxygen donor atoms and one oxygen atom to complete the $\mathrm{N}_{2} \mathrm{O}_{3}$ coordination sphere. The geometry can be considered as a distorted square pyramidal coordination with $\mathrm{N} 1, \mathrm{O} 1, \mathrm{~N} 2$ and $\mathrm{O} 2$ of the Schiff base 
complex. The distances between the coordinated nitrogen and oxygen atoms with the metal center do not significantly differ (Table 3).

The $\mathrm{C}=\mathrm{N}$ bond distances are 1.308(7) $\AA(\mathrm{N} 1=\mathrm{C} 7)$ and 1.300(7) $\AA(\mathrm{N} 2=\mathrm{C} 14)$, which are consistent with a slight elongation of the $\mathrm{C}=\mathrm{N}$ double bond in the corresponding ligand [64, 49]. The $\mathrm{V}-\mathrm{O}$ bond lengths of 1.888(4) and 1.929(4) $\AA$ and the $\mathrm{V}-\mathrm{N}$ bond lengths of 2.062(5) and 2.058(5) $\AA$ are similar to those given in related Schiff base oxovanadium complexes [64-67]. The $\mathrm{V}-\mathrm{O}$ bond distances are shorter than $\mathrm{V}-\mathrm{N}$, which indicates stronger coordination of the oxygen atoms.

The $\beta$-angle $\mathrm{N} 1-\mathrm{V} 1-\mathrm{N} 2$ is $78.33(19)$ and the $\alpha$-angle $\mathrm{O} 1-\mathrm{V} 1-\mathrm{O} 2$ is $89.30(19)$. Thus, the phenolate oxygens are displaced out of the "equatorial" plane away from the axial oxo ligand.The oxovanadium $\mathrm{V}=\mathrm{O}$ bond distance is $1.604(4)$, which is a typical value for vanadyl compounds $[68,69]$.

The two phenolate ring moieties of the complex are not coplanar with the above coordination plane (N1-N2-O1-O2) and bend to the same side. The packing structure of VO(IV)L consists of a discrete molecule held together by Van Der Waals forces (Fig.4).

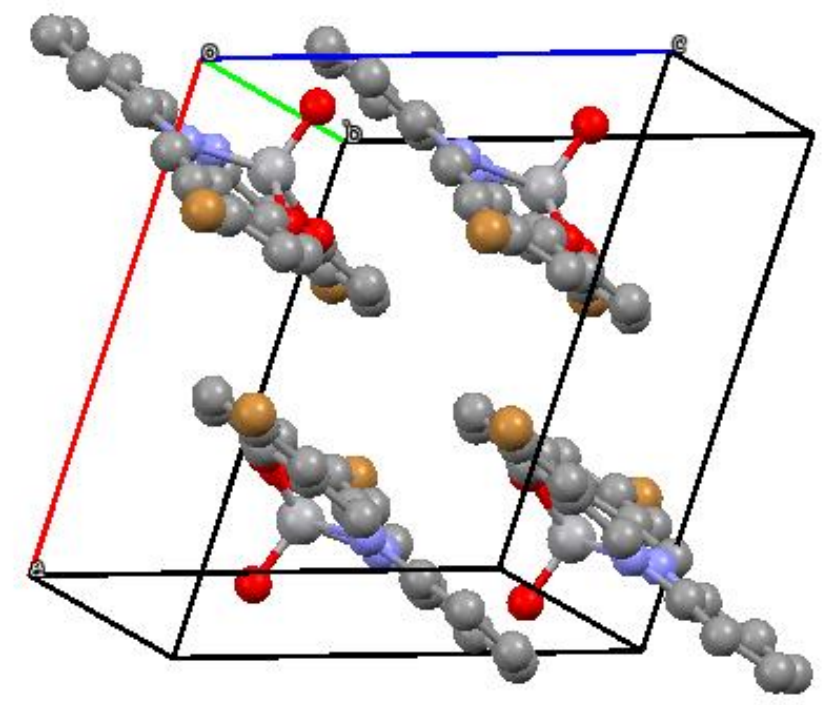

Fig. 4. Schematic drawing of the crystal packing

Table .4.

Selected bond lengths $(\AA)$ and bond angles $\left(^{\circ}\right)$ for VO(IV)L complex.

\begin{tabular}{lllll}
\hline Bond lenghts $(\AA)$ & Bond angles $\left(^{\circ}\right)$ & \\
\hline N1-V1 & $2.062(5)$ & O3-V1-O1 $109.8(2)$ & O2-V1-N2 & $87.61(18)$ \\
N2-V1 & $2.058(5)$ & O3-V1-O2 $108.5(2)$ & O3-V1-N1 104.4 (2) \\
O1-V1 $1.888(4)$ & O1-V1-O2 $89.30(19)$ & O1-V1-N1 85.86 (19) \\
O2-V1 $1.929(4)$ & O3-V1-N2 $103.4(2)$ & O2-V1-N1 146.4 (2) \\
O3-V1 $1.604(4)$ & O1-V1-N2 $145.9(2)$ & N2-V1-N1 78.33 (19) \\
\hline
\end{tabular}




\subsection{DFT Calculations}

The computational study was carried out starting from the X-ray crystallographic molecular structures of VO(IV)L complex and $\mathbf{H}_{2} \mathbf{L}$ ligand

Recent investigations have shown that the Becke's three parameter hybrid functional using the LYP correlation functional [70] (B3LYP) method [71] is reliable for the description of geometrical parameters, electronic structure and optical properties of different molecules and complexes [7276]. In the present density functional theory (DFT) calculations, the B3LYP functional was adopted together with one set of two polarization functions (TZ2P) as the basis sets and none frozen cores in all calculations. Relativistic corrections were taken into account with the use of the relativistic scalar zero-order-regular approximation (ZORA) method [77, 78]. The numerical integration parameter was done with the Beckegrid option fixed to the quality very good $[79,80]$. The energy convergence criterions were $1 \mathrm{e}^{-4}$ au. All quantum chemistry calculations were performed with Amsterdam Density Functional (ADF) program developed by Baerends and co-workers [81- 83]. All structures were calculated in their ground state without any symmetry constraints. No imaginary vibrational frequencies were found for $\mathbf{V O}(\mathbf{I V}) \mathrm{L}$ and $\mathrm{H}_{2} \mathrm{~L}$ optimized geometries.

The important optimized geometrical parameters (distance and angle) of the VO(IV)L and $\mathbf{H}_{2} \mathbf{L}$ calculated using the density functionals B3LYP are presented in Fig. 5 and Table.5.
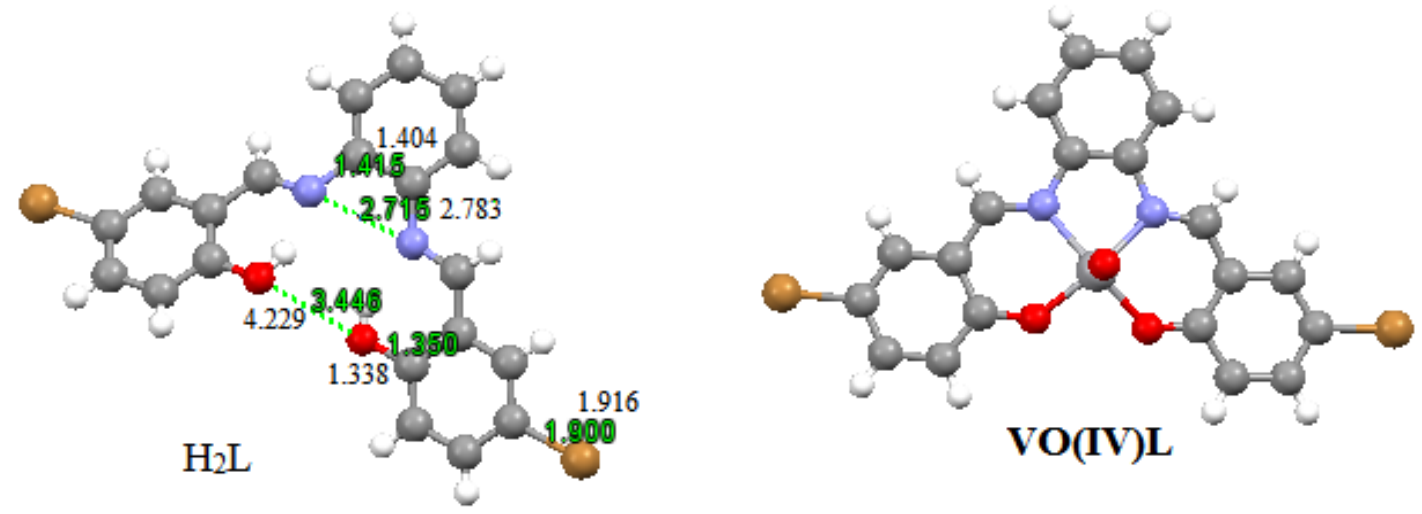

Fig.5. DFT optimized geometries of $\mathbf{H}_{2} \mathbf{L}$ and $\mathbf{V O}(\mathbf{I V}) \mathbf{L}$, with important bond lengths $(\AA)$ of ligand. Experimental data are given in green.

Table.5. Selected Bond Lengths $(\AA)$ and Angles $\left(^{\circ}\right)$ of VO(IV)L complex

\begin{tabular}{ccc}
\hline & Exp & B3LYP/TZ2P \\
\hline V-N1, 2 & 1.887 & 1.945 \\
V-O1,2 & 2.063 & 2.100 \\
V-O3 & 1.604 & 1.579 \\
C1-C6 & 1.396 & 1.407 \\
Cent ${ }^{*}-\mathrm{V}$ & 0.582 & 0.628 \\
Br-C10,17 & 1.893 & 1.915
\end{tabular}




\begin{tabular}{ccc}
$\mathrm{N} 1-\mathrm{V}-\mathrm{N} 2$ & 78 & 77 \\
$\mathrm{O} 1-\mathrm{V}-\mathrm{O} 2$ & 89 & 88 \\
$\mathrm{O} 1-\mathrm{N} 1-\mathrm{N} 2-\mathrm{O} 2$ & 0.11 & 0.0 \\
\hline * centroid between $O-N-N-O$
\end{tabular}

As seen in Fig.5, the deviations between theoretical result and experimental geometry parameters of $\mathbf{H}_{2} \mathbf{L}$ ligand are in satisfactory agreement with experimental results. For the VO(IV)L complex, the V-O3 distance is significantly shorter than the V-O1,2, as observed in the solid state. In addition, the dihedral angle O1-N1-N2-O2 and angles $\mathrm{N} 1-\mathrm{V}-\mathrm{N} 2$ and $\mathrm{O} 1-\mathrm{V}-\mathrm{O} 2$ are same in the solid state. More generally, the average bond lengths $\mathrm{V}-\mathrm{O}, \mathrm{V}-\mathrm{N}, \mathrm{Br}-\mathrm{C}$ and $\mathrm{C}-\mathrm{C}$ calculated by B3LYP/TZ2P method are systematically a little longer than the experimental. Our calculated results of distance and angles agree well with the experimental data. This agreement, if it was necessary, clearly supports the ability of B3LYP/TZ2P to accurately reproduce the structure of $\mathbf{H}_{2} \mathbf{L}$ and VO(IV)L.

In Table.6, we display the computed values of the electronic chemical potential $(\mu)$, chemical hardness ( $\eta$ ), global electrophilicity $(\omega)$ indices and IP of $\mathbf{H}_{2} \mathbf{L}$ and VO(IV)L.

The global hardness $(\eta)$ measures the stability of a system in terms of resistance to electron transfer and the chemical potential $(\mu)$ characterises the escaping tendency of electrons from the equilibrium system. Each system's $(\eta)$ and $(\mu)$ are calculated from the energy of HOMO and LUMO [84-87]:

$\mu=\frac{1}{2}\left(\varepsilon_{H}+\varepsilon_{L}\right)$

$\eta=\varepsilon_{L}-\varepsilon_{H}$

the global electrophilicity index $(\omega)$ expresses the ability of a molecule to accept electrons from the surroundings [88]:

$\omega=\frac{\mu^{2}}{2 \eta}$

According to the absolute scale of global electrophilicity power $(\omega)$ reported by Domingo et al. [89], the $\mathrm{H}_{2} \mathrm{~L}$ ligand can be classified as strong electrophiles (see Table.6).

Table.6. Global reactivity descriptors: chemical potential $(\mu, \mathrm{eV})$, chemical hardness $(\eta$, eV) and electrophilicity index $(\omega)$.

\begin{tabular}{lcc}
\hline & $\mathrm{H}_{2} \mathrm{~L}$ & $\mathrm{VO}(\mathrm{IV}) \mathrm{L}$ \\
\hline$\mu(\mathrm{eV})$ & -4.472 & -4.65 \\
$\eta(\mathrm{eV})$ & 4.052 & 3.65
\end{tabular}


Time dependent density functional theory (TD-DFT) calculations were performed in order to understand these spectroscopic data. The molecular orbital energy diagrams of $\mathbf{H}_{2} \mathbf{L}$ and VO(IV)L are shown in Figures.2.a-b, respectively, and the corresponding electronic transitions are listed in Table.7.

Table.7. Calculated Lowest Excitations TD- DFT for $\mathrm{H}_{2} \mathrm{~L}$ and VO(IV)L. B3LYP/TZ2P level of theory

\begin{tabular}{|c|c|c|c|}
\hline \multicolumn{4}{|c|}{$\mathrm{H}_{2} \mathrm{~L}$} \\
\hline$\lambda(\mathrm{nm})$ & $f$ & Type & composition \\
\hline 373.5 & 0.294 & $\pi \rightarrow \pi^{*}, \mathrm{n} \rightarrow \pi^{*}$ & $\mathrm{HOMO} \rightarrow \mathrm{LUMO}$ \\
\hline 344.52 & 0.108 & $\pi \rightarrow \pi^{*}, \mathrm{n} \rightarrow \pi^{*}$ & HOMO- $1 \rightarrow$ LUMO \\
\hline 325.44 & 0.159 & $\pi \rightarrow \pi^{*}$ & $\mathrm{HOMO} \rightarrow \mathrm{LUMO}+1$ \\
\hline 289.21 & 0.117 & $\pi \rightarrow \pi^{*}$ & HOMO-3 $\rightarrow$ LUMO \\
\hline 271.32 & 0.280 & $\pi \rightarrow \pi^{*}$ & HOMO-4 $\rightarrow$ LUMO \\
\hline 256.101 & 0.228 & $\pi \rightarrow \pi^{*}$ & HOMO-5 $\rightarrow$ LUMO \\
\hline \multicolumn{4}{|c|}{$\mathrm{VO}(\mathrm{IV}) \mathrm{L}$} \\
\hline \multirow[t]{2}{*}{410.49} & 0.055 & $\pi \rightarrow \pi^{*}$ & $\mathrm{SOMO} \beta \rightarrow \mathrm{SUMO} \beta$ \\
\hline & & $\pi \rightarrow \pi^{*}, \mathrm{n} \rightarrow \pi^{*}$ & $\mathrm{SOMO} \alpha \rightarrow \mathrm{SUMO} \alpha+1$ \\
\hline \multirow[t]{3}{*}{424.02} & 0.126 & $\pi \rightarrow \pi^{*}$ & SOMO $\beta-1 \rightarrow$ SUMO \\
\hline & & $\pi \rightarrow \pi^{*}$ & $\mathrm{SOMO} \alpha \rightarrow \mathrm{SUMO} \alpha$ \\
\hline & & MLCT & $\mathrm{SOMO} \alpha-2 \rightarrow \mathrm{SUMO} \alpha$ \\
\hline 554.11 & 0.0001 & ICMT & $\mathrm{SOMO} \alpha-2 \rightarrow \mathrm{SUMO} \alpha+3$ \\
\hline \multirow[t]{2}{*}{589.79} & 0.0003 & ICMT & $\mathrm{SOMO} \alpha-2 \rightarrow \mathrm{SUMO} \alpha+4$ \\
\hline & & MLCT & $\mathrm{SOMO} \alpha-2 \rightarrow \mathrm{SUMO} \alpha+1$ \\
\hline
\end{tabular}




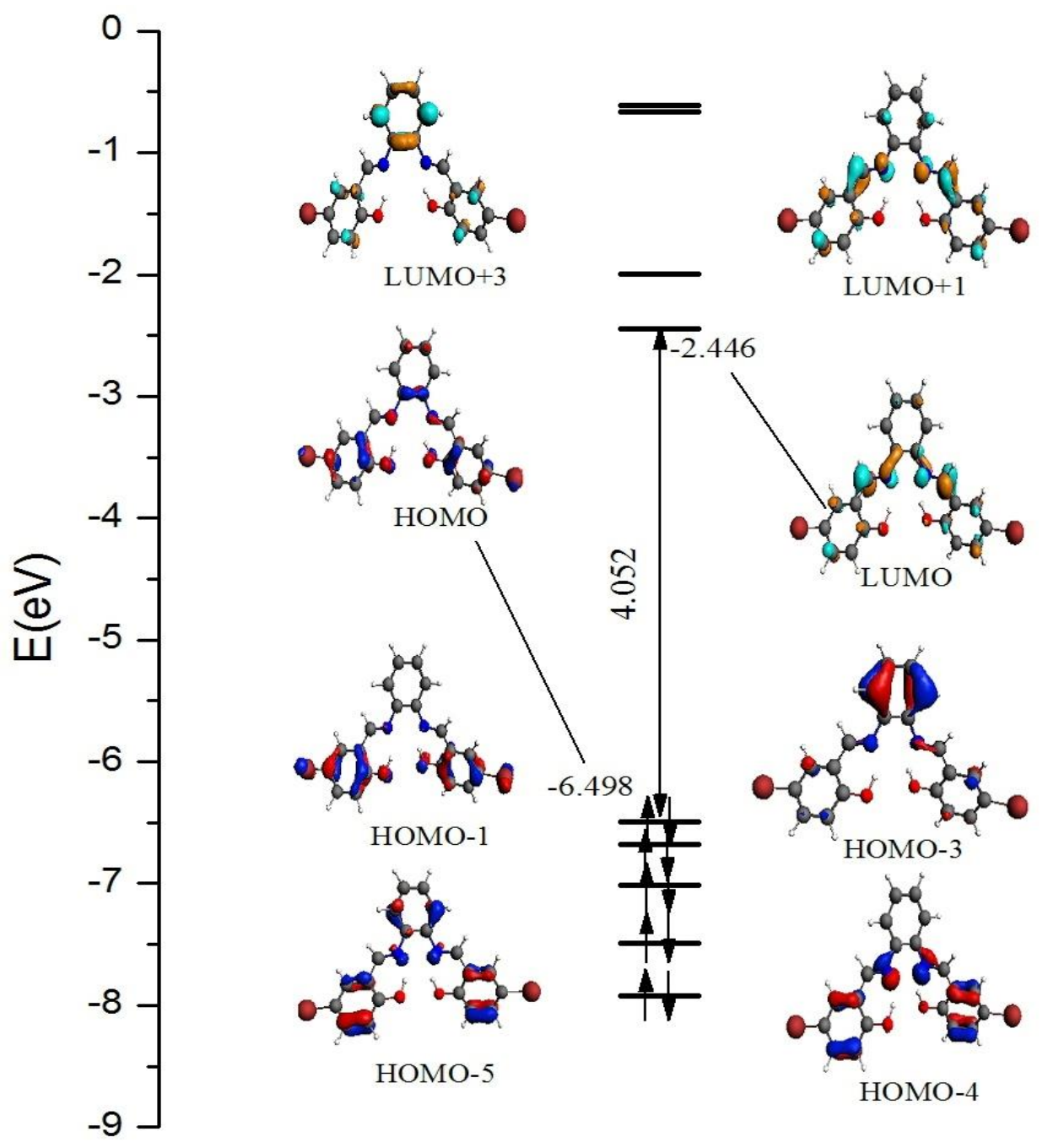

Fig.2.a. Molecular orbital energy diagram for $\mathrm{H}_{2} \mathrm{~L}$ (B3LYP/TZ2P). 

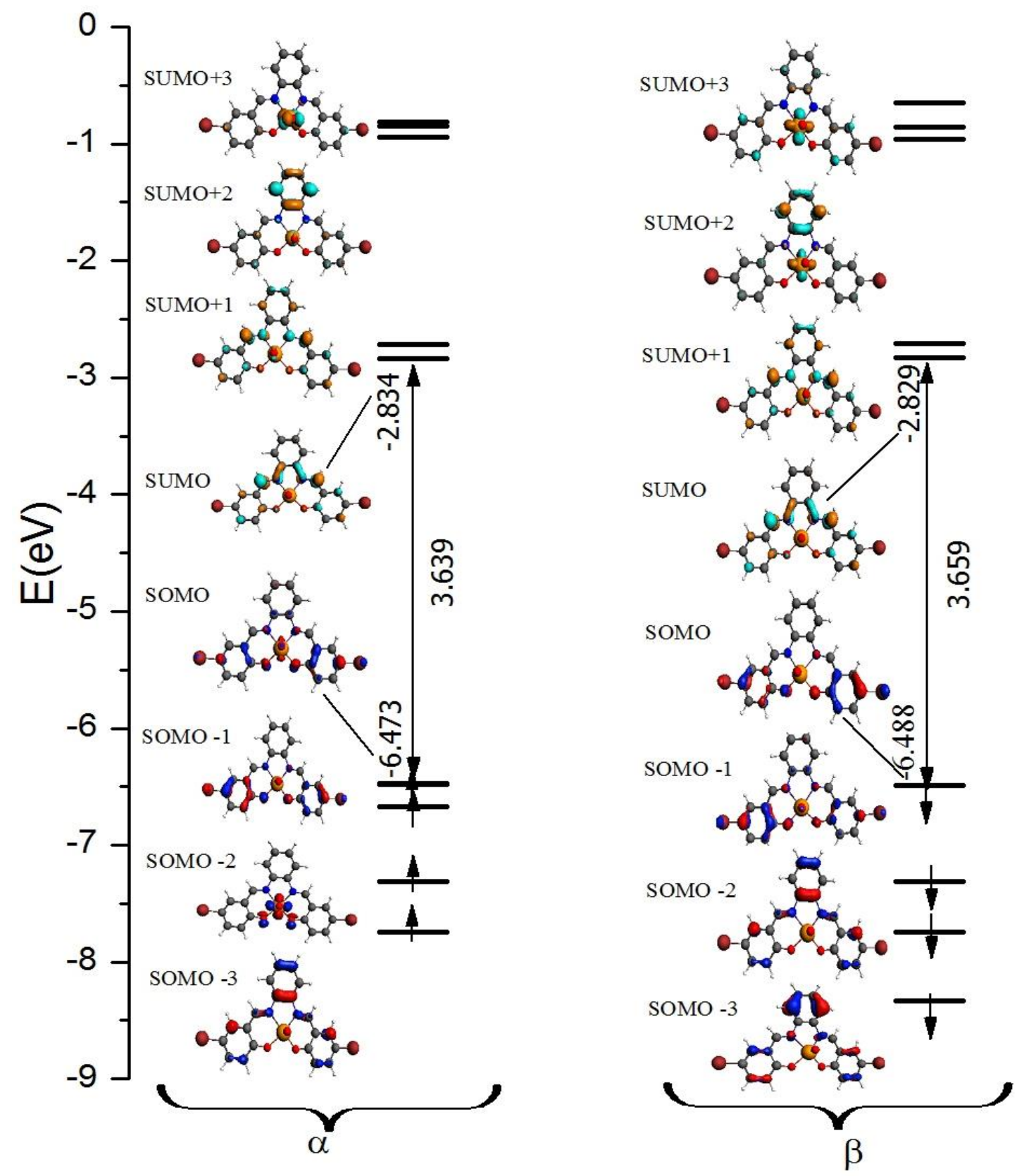

Fig.2.b. DFT molecular orbital diagrams of SOMO and SUMO of $\alpha$ and $\beta$ spin of VO(IV)L complex (the energies are given in eV). B3LYP/TZ2P level of theory.

The lowest energy transition of $\mathbf{H}_{2} \mathbf{L}$ (at 373 and $344 \mathrm{~nm}$ ) involves exclusively $(99 \%)$ the HOMO and HOMO-1,respectevely, localized on the donor part of the ligand, and the LUMO, delocalized on the two aromatic rings (see Figure 2.a). Thus, these transition can be classically described as an intramolecular charge transfer (ICT) corresponds to the $\pi \rightarrow \pi^{*}$ with some minor $\mathrm{n} \rightarrow \pi^{*}$ transition $(\mathrm{HOMO} \rightarrow \mathrm{LUMO})$. The optical transition centered at 325, 289, 271 and $256 \mathrm{~nm}$ can be assigned to a $\pi \rightarrow \pi^{*}$ transition (see fig. 2-a). On the other hand the experimental lowestenergy absorption maximum of this ligand are observed at 267 and $343 \mathrm{~nm}$. From these results, we can say that there is a good agreement between the experimental data and excitation calculations. 
Our TD-DFT calculations obtained for VO(IV)L complex predict that the transition $\pi \rightarrow \pi^{*}$ and $\mathrm{n} \rightarrow \pi^{*}$ are located at 410 and $424 \mathrm{~nm}$ are dominated by the $\{\mathrm{SOMO} \beta \rightarrow$ SUMO $\beta$, SOMO $\alpha \rightarrow$ $\mathrm{SUMO} \alpha+1\}$ and $\{\mathrm{SOMO} \beta-1 \rightarrow \mathrm{SUMO}, \mathrm{SOMO} \alpha \rightarrow \mathrm{SUMO} \alpha\}$ respectively (see Fig.2.b). Furthermore, the electronic transition arise from the metal toward the ligand orbitals (metal to ligand charge transfer MLCT) at $424 \mathrm{~nm}$ is dominated by the SOMO $\alpha-2 \rightarrow \mathrm{SUMO} \alpha$ and $f=0.126$ (see table 3). On the other hand, the excitations from the SOMO $\alpha-2 \rightarrow \mathrm{SUMO} \alpha+3$ and SOMO $\alpha-$ $2 \rightarrow$ SUMO $\alpha+4$ are intra-charge metal transfer (ICMT character) bonds at 554 and $589 \mathrm{~nm}$ but the oscillator strengths are zero. These results agree well with experimental and confirmed that the $\operatorname{ICMT}(\mathrm{d} \rightarrow \mathrm{d})$ transition completely absent in VO(IV)L complex.

\subsection{Thermal analysis}

The thermal properties of the Schiff base and the corresponding complex were investigated by thermo gravimetric analyses TGA and DTA measurements to get information about the thermal stabilities whether the water molecules are inside or outside the inter coordination sphere of the central metal ion and to suggest a general scheme for thermal decomposition of this complex.

At a heating rate of $10{ }^{\circ} \mathrm{C} / \mathrm{min}$ under a nitrogen atmosphere the temperature was increased from ambient to $950{ }^{\circ} \mathrm{C}$. The absence of weight loss up to $80{ }^{\circ} \mathrm{C}$ indicates that there is no water molecule in the crystalline form $[90,91]$. Also, the TGA showed no weight loss up to $150{ }^{\circ} \mathrm{C}$ indicating that the water molecule is not coordinated to complex $[92,93]$.

The complex was decomposed in two steps (Fig. 7). The first step occurs between 343 and $414{ }^{\circ} \mathrm{C}$ and was attributed to the release of $\mathrm{C}_{6} \mathrm{H}_{4} \mathrm{~N}_{2}$, as indicated by the mass loss of $19.31 \%$ (calculated 18.56\%). The second step occurs $414-661^{\circ} \mathrm{C}$, a mass loss of $64.15 \%$ (calculated $68.26 \%$ ) due to the elimination of $\mathrm{C}_{14} \mathrm{H}_{8} \mathrm{O}_{2} \mathrm{Br}_{2}$ group, with the formation of metal oxide [48]. 


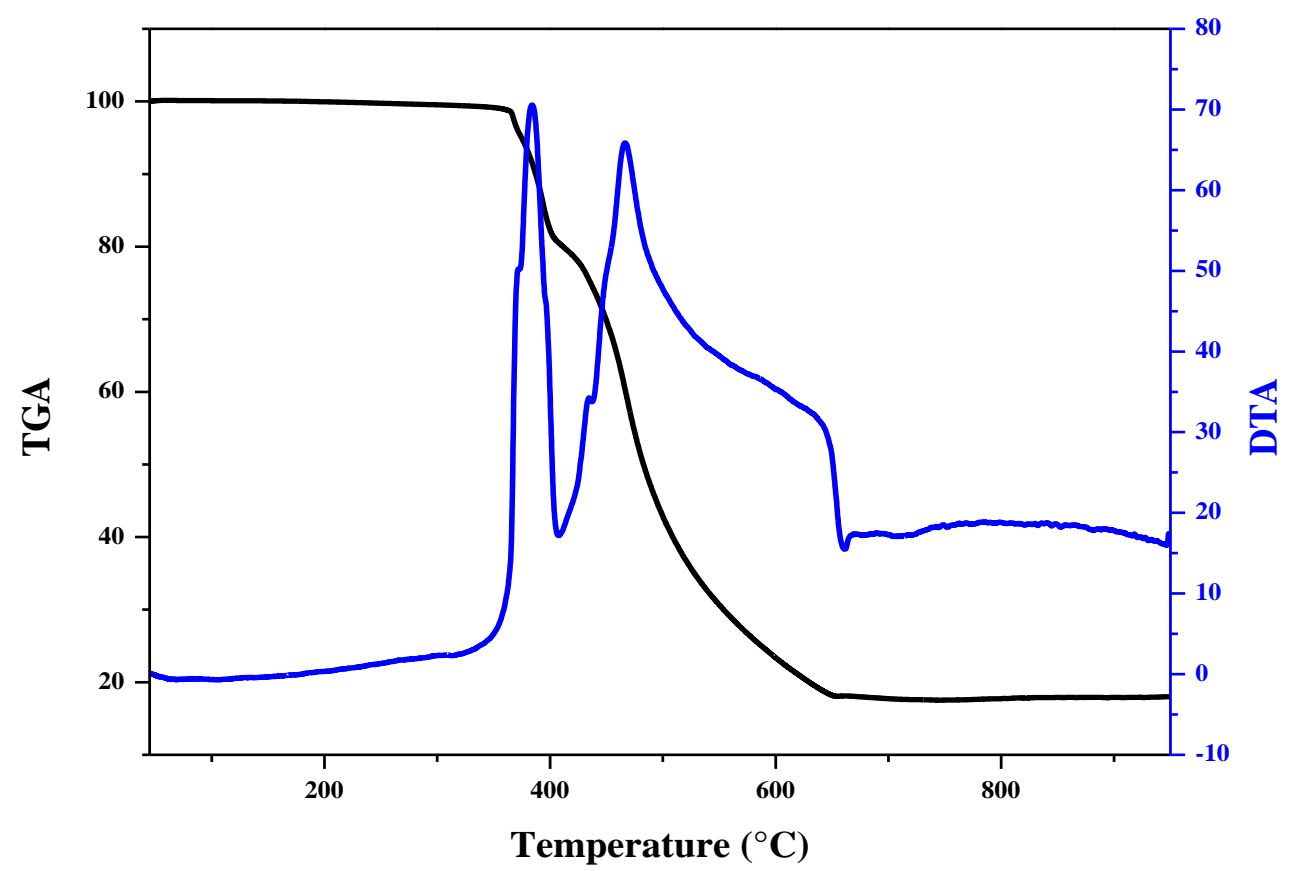

Fig.7. TGA and DTA spectrum of the oxovanadium complex VO(IV)L.

\subsection{Electrochemical measurements}

The electrochemical behavior of the ligand $\mathrm{H}_{2} \mathrm{~L}$ and the complex $\mathrm{VO}(\mathrm{IV}) \mathrm{L}$ was investigated by cyclic voltammetry with a glassy carbon (GC) electrode in DMF solution containing $10^{-1} \mathrm{M}$ $\mathrm{LiClO}_{4}$ as the supporting electrolyte, under nitrogen saturated atmosphere in the potential range 2200 to $1600 \mathrm{mV} / \mathrm{SCE}$. The Fc/Fc ${ }^{+}$, redox couple of ferrocene was used as an internal standard. The cyclic voltammograms of $\mathbf{V O}(\mathbf{I V}) \mathbf{L}$ complex are given in Fig 8c and exhibits a quasi-reversible waves at $\mathrm{E}_{1 / 2}=606 \mathrm{mV}$, attributed to the one-electron $\mathrm{VO}^{\mathrm{IV}} / \mathrm{VO}^{\mathrm{V}}$ oxidation couple [94], in which the VO is coordinated by a chelated ligand containing $\mathrm{N}$-amine and O-phenolate donor atoms. Which are absent in the CV of the free ligand.

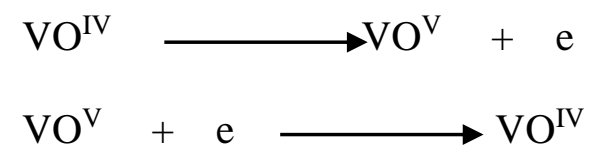

On the other hand, the first irreversible reduction at $\mathrm{E}_{\mathrm{red}}=-1093 \mathrm{mV} / \mathrm{SEC}$ is assigned to the $\mathrm{VO}^{\mathrm{IV}} / \mathrm{VO}^{\mathrm{III}}$ [95], the second irreversible reduction wave occurred at $\mathrm{E}_{\mathrm{red}}=-1598 \mathrm{mV} / \mathrm{SCE}$ is due to the reduction of the azomethine groups. [96,97] 


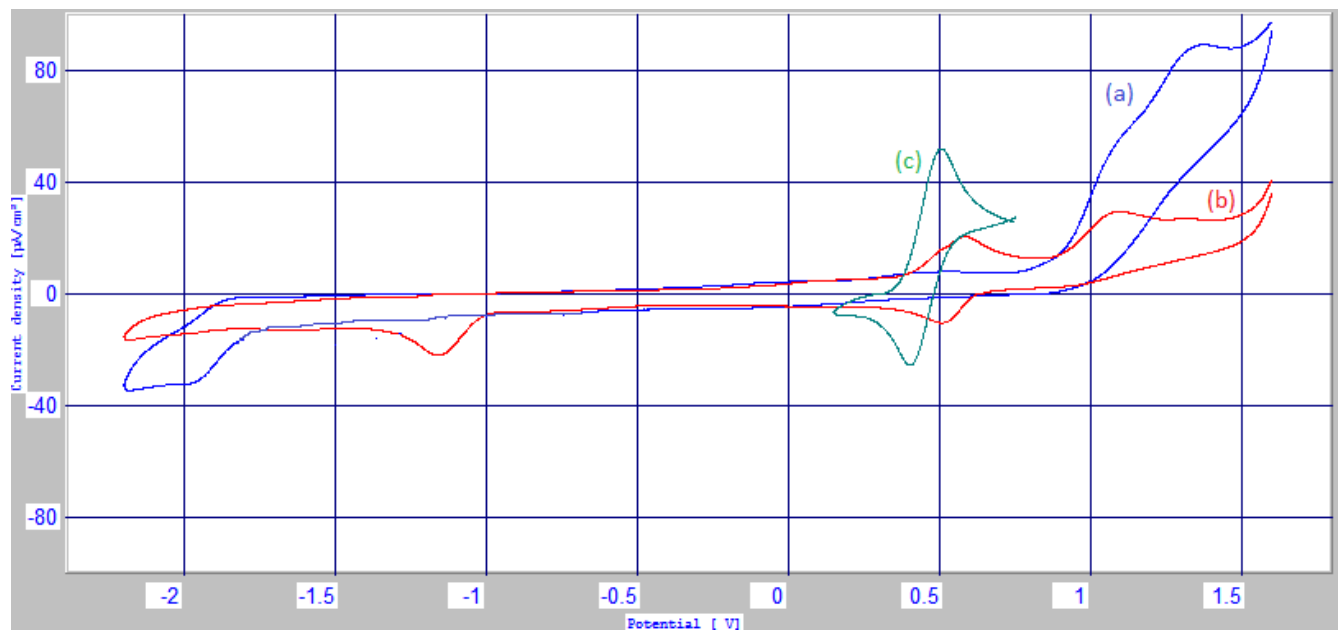

Fig.8. Cyclic voltammograms of $\mathrm{H}_{2} \mathrm{~L}$ ligand (a), VOL complex (b) and $\mathrm{Fc} / \mathrm{Fc}^{+}(\mathrm{c})$ in $0.1 \mathrm{M} \mathrm{LiClO}_{4} / \mathrm{DMF}$ solution at scan rate of $100 \mathrm{mVs}^{-1}$.

A typical cyclic voltammogram of complex in the potential range from 200 to $900 \mathrm{mV} / \mathrm{SCE}$ is shown in Fig.9. Multiple scans which resulted in nearly superposable cyclic voltammograms show that the five coordinates geometry is stable in both oxidation states, at least on the cyclic voltammetry time scale. The result revealed that the redox process of studied vanadium Schiff base complex is a one-electron transfer reaction. The results of cyclic voltammetry (CV) measurements are given in Table 7 .

The square root of the scan rate exhibits a linear relation with the current peak Ip (inset of Fig.9). The Ip/v ${ }^{1 / 2}$ value is almost constant for all scan rates. This establishes the electrode process as diffusion controlled [98].

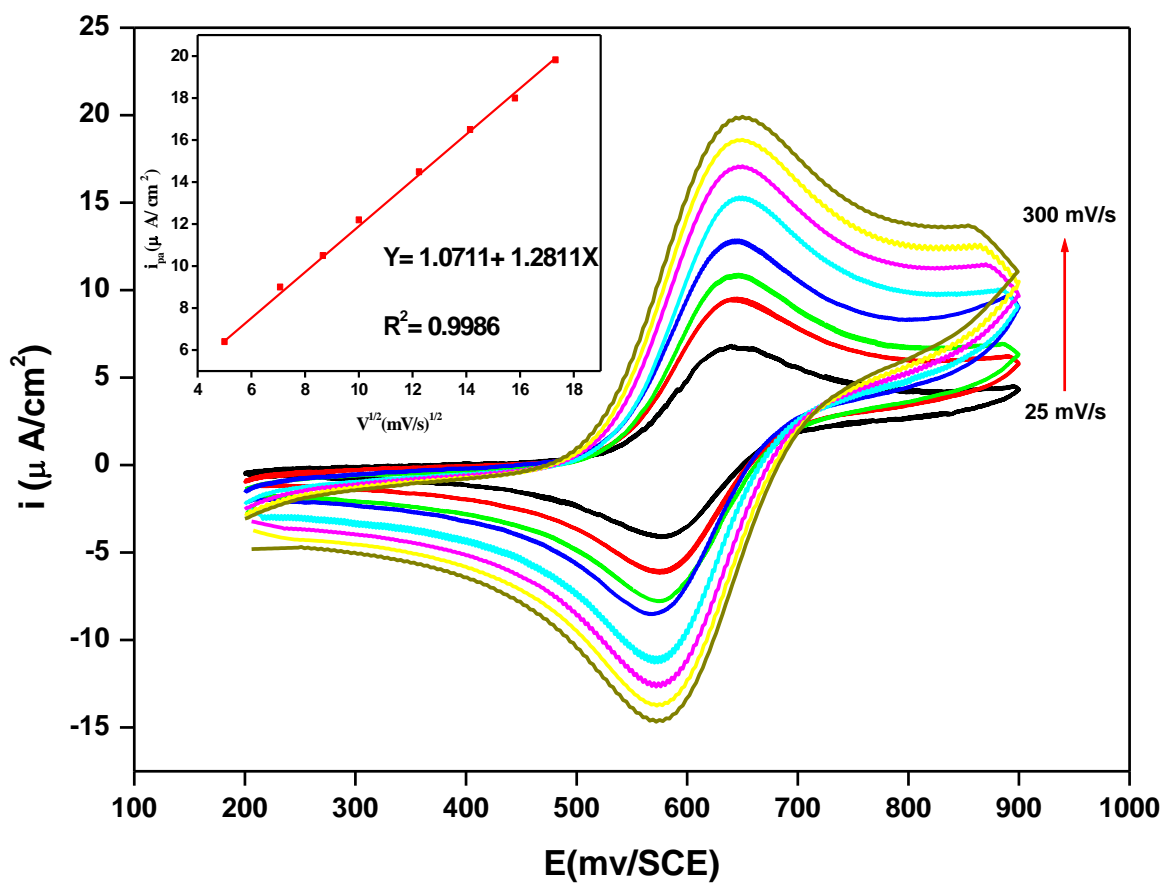

Fig.9. $\mathrm{CV}$ of $10^{-3} \mathrm{M}$ of VOL in $\mathrm{DMF} / 10^{-1} \mathrm{M} \mathrm{LiClO}_{4}$ at various scan rates from 25 to $300 \mathrm{mV} / \mathrm{s}$. The inset shows the anodic peak current $\left(\mathrm{i}_{\mathrm{pa}}\right) \mathrm{vs}$. $v^{1 / 2}$. 
The variation of the scan rate between 200 and $900 \mathrm{mVs}^{-1}$ only showed a marginal increase in $\Delta \mathrm{Ep}$. At a scan rate of $100 \mathrm{mV} / \mathrm{s}$, the separation between cathodic and anodic peaks $(\Delta \mathrm{Ep} \approx 72 \mathrm{mV})$ is suggestive of a one electron- process. The ipa/ipc ratio was closest to 1 indicating chemical reversibility system.

Table.7. Cyclic voltammetric parameters for the oxovanadium VO(IV)L complex in different scan rates

\begin{tabular}{cccccccc}
\hline $\mathrm{v}$ & $\mathrm{E}_{\mathrm{pa}}$ & $\mathrm{E}_{\mathrm{pc}}$ & $\Delta \mathrm{E}_{\mathrm{p}}$ & $\mathrm{E}_{1 / 2}$ & $\mathrm{i}_{\mathrm{pa}}$ & $\mathrm{i}_{\mathrm{pc}}$ & $\mathrm{i}_{\mathrm{pa}} / \mathrm{i}_{\mathrm{pc}}$ \\
\hline 25 & 639.8 & 576.1 & 63.7 & 607.9 & 6,4 & 4.66 & 1.37 \\
50 & 642.6 & 573.3 & 69.3 & 607.9 & 9 & 6.70 & 1.34 \\
75 & 645.1 & 573.1 & 72.0 & 609.1 & 10,5 & 7.79 & 1.34 \\
100 & 642.6 & 570.8 & 71.8 & 606.7 & 12,2 & 9.10 & 1.34 \\
150 & 647.8 & 571.7 & 76.1 & 609.7 & 14,49 & 11.00 & 1.31 \\
200 & 648.7 & 572.6 & 76.1 & 610.6 & 16,5 & 12.66 & 1.30 \\
250 & 648.7 & 569.7 & 79.0 & 609.2 & 18 & 14.14 & 1.27 \\
300 & 650.6 & 571.7 & 78.9 & 611.1 & 19,82 & 15.4 & 1.28 \\
\hline
\end{tabular}

\subsection{Rotating disk electrode voltammetric studies}

In order to determine the diffusionnal character of the complex, a linear sweep hydrodynamics voltammetry on rotating disk electrode (RDE), using GC working electrode, is carried out in order to determine the diffusion coefficient D. We have studied the evolution of the current cathodic as a function of the potential $\mathrm{I}_{\mathrm{c}}=\mathrm{f}(\mathrm{E})$ at different rotation rate of the disc, from 250 to $3000 \mathrm{rpm}$, in the interval 300 to $800 \mathrm{mV} / \mathrm{ECS}$ for a scan rate of $20 \mathrm{mV} / \mathrm{s}$. The current potential curves and the Levich plots are shown in Fig. 10.

Under the studied conditions, a linear correlation between the limiting current and the square root of the rotating rate is observed, which leads to the determination of the value of the proportionality constant using Levich equation for a one electron $\mathrm{VO}^{\mathrm{V}} / \mathrm{VO}^{\mathrm{IV}}$ reduction [99]. Diffusion coefficient was calculated from the slope of the $i_{\text {lim }}$ vs. $\omega^{1 / 2}$ plots and its value is $2.10^{-6}$ $\mathrm{cm}^{2} / \mathrm{s}[97]$. 


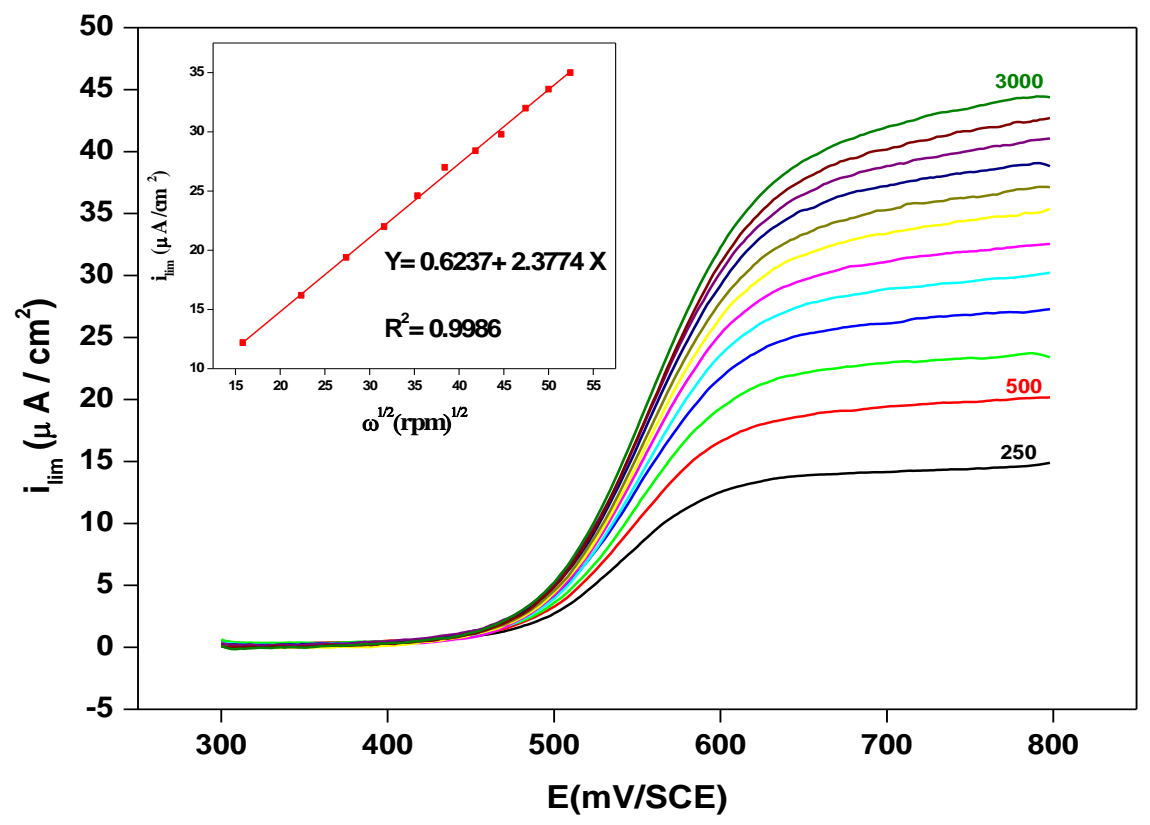

Fig. 10. Voltammograms of $\mathbf{V O}(\mathbf{I V}) \mathbf{L}$ complex at RDE of GC in DMF solution. Rotation rates: from 250 to $3000 \mathrm{rpm}$. The inset shows the Levich plot.

\section{Catalytic activity}

The catalytic activity and selectivity of the VO(IV)L have been studied for the oxidation of cyclohexene with $\mathrm{H}_{2} \mathrm{O}_{2}$ and $\mathrm{O}_{2}$ as oxidants in DMF, under similar experimental conditions [ 100 ].

The oxidation reactions give 2-cyclohexenone as the main product, 2-cyclohexenol and cyclohexene epoxide in small yields which are evidently identified using gas chromatography by comparison with standards (Fig.11). In order to obtain maximum conversion of cyclohexene, the catalytic reactions were carried out using two oxidants.

The results of the catalytic oxidation of cyclohexene by $\mathrm{H}_{2} \mathrm{O}_{2}$ and $\mathrm{O}_{2}$ in the presence of VO(IV)L are shown in table 8, which shows the variation of product yield with the oxidant nature. Higher yield was obtained for 2-cyclohexenone than 2-cyclohexenol and cyclohexene epoxide for the $\mathrm{H}_{2} \mathrm{O}_{2}$ oxidant. In the case of $\mathrm{O}_{2}$, as oxidant, the yields for cyclohexenol and cyclohexene epoxide were nearly similar. The yield of the three products increased, but level off with time. This level off is most likely due to the degradation of the VO(IV)L catalyst by the oxidant with time.

Table .8. Catalytic oxidation of cyclohexene by $\mathrm{H}_{2} \mathrm{O}_{2}$ and $\mathrm{O}_{2}$ in the presence of VO(IV)L

\begin{tabular}{|c|c|c|c|c|c|}
\hline \multirow{2}{*}{ Catalyst } & \multirow{2}{*}{ Oxidant } & \multirow{2}{*}{$\%$ Conversion } & \multicolumn{3}{|c|}{ \%Sélectivity } \\
\hline & & & Epoxide & Cyclohexene-ol & Cyclohexene-one \\
\hline \multirow{3}{*}{ VO(IV)L } & $\mathbf{H}_{2} \mathbf{O}_{2}$ & 80 & 9.71 & 26.72 & 63.56 \\
\hline & $\mathbf{O}_{2}$ & 85 & 3.21 & 23.62 & 73.16 \\
\hline & Oxidant Free & - & - & - & - \\
\hline
\end{tabular}


The nature and the relative yields of the products, formed by catalytic oxidation of cyclohexene using oxovanadium Schiff base complex, vary considerably depending with the oxidant nature. This work shows that the $\mathbf{V O}(\mathbf{I V}) \mathbf{L}$, as catalyst, in the presence of $\mathrm{O}_{2}$ and $\mathrm{H}_{2} \mathrm{O}_{2}$ oxidants, favored the formation of 2-cyclohexenone to the rest of the products (fig. 11).

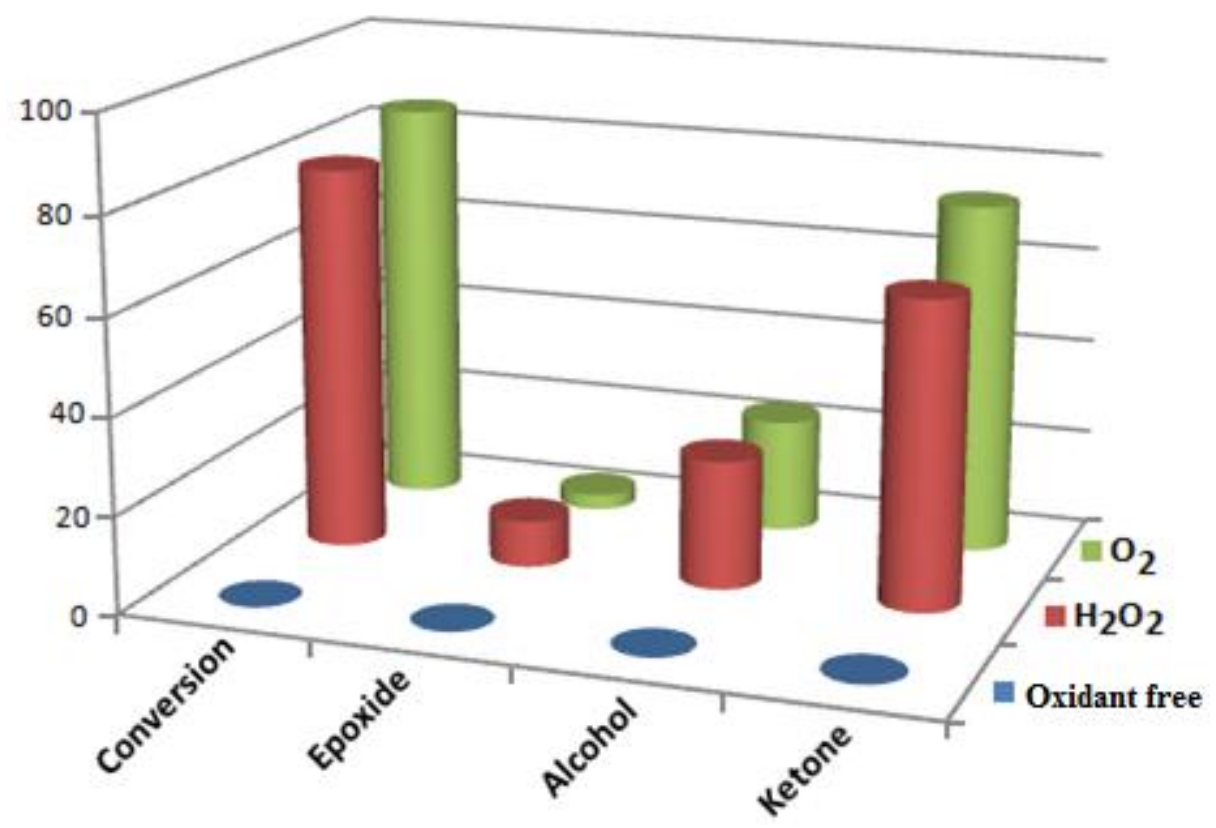

Fig. 11. The oxidant effect on the oxidation of cyclohexene.

The results show that the activity of the oxovanadium complex in the oxidation of cyclohexene in the presence of $\mathrm{O}_{2}$ in DMF is much higher than in the presence of $\mathrm{H}_{2} \mathrm{O}_{2}$ in DMF, the trend of the observed oxidant effect was $\mathrm{O}_{2}>\mathrm{H}_{2} \mathrm{O}_{2}$. This may be related to the ability of $\mathrm{O}_{2}$ and inability of $\mathrm{H}_{2} \mathrm{O}_{2}$ to mix with the organic substrate phase [101].

In the proposed mechanism, it seems that active oxidant is oxovanadium(V) initially formed by oxidation of oxovanadium(IV) in the presence of $\mathrm{O}_{2}$ (Scheme 2) [102]. $\mathrm{O}_{2}$ coordinate to the $\mathrm{V}^{\mathrm{V}} \mathrm{O}$ species to form $\mathrm{V}^{\mathrm{V}}-\mathrm{O}-\mathrm{O}^{-}$intermediate, which can react with olefin to yield oxide product.

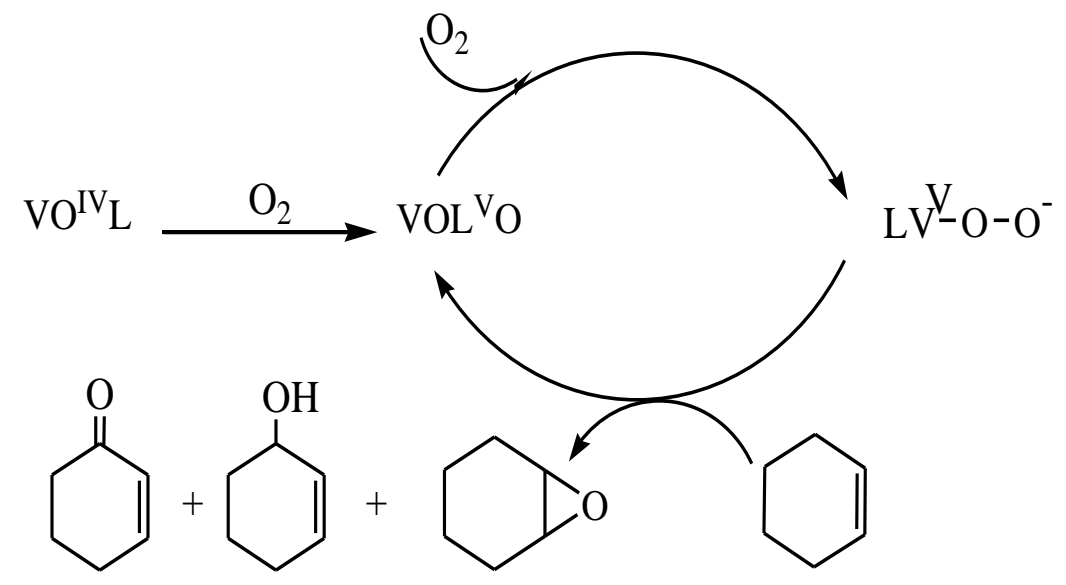

Scheme.2. Proposed catalytic cycle for the oxidation of cyclohexene by VO(IV)L 


\section{Conclusion}

New five-coordinate oxovanadium (V) complex derived from Schiff base ligand containing the $\mathbf{N}_{2} \mathrm{O}_{2}$ donor group successfully synthesized with high purity and yield, $\mathbf{9 0 \%}$ for $\mathbf{H}_{2} \mathrm{~L}$ and $\mathbf{8 4 \%}$ for $\operatorname{VO}(\mathbf{I V}) \mathbf{L}$, and characterized with the aid of FT-IR, UV-Vis, and mass spectrometric techniques, along with elemental and thermal analyses. The spectroscopic analysis confirmed the composition and the structure of the newly obtained compound.

The non-electrolytic nature of the VO(IV)L complex was confirmed on the basis of their molar conductance value.

The thermo gravimetric analysis TGA and differential thermoanalysis DTA, are consistent with the proposed structures and provided unambiguous evidence for no coordinated water in the ligand and its complex, and showed that the compound is thermally stable up to $\mathbf{3 4 0}^{\circ} \mathbf{C}$ for VO(IV)L, $2^{\circ 2}{ }^{\circ}$ for $\mathbf{H}_{2} L$. X-ray analysis reveals that VO(IV)L has a distorted square-pyramid geometry.

The calculation confirms that calculated geometrical parameters are in agreement with the experimental data.

Electrochemical studies by the cyclic voltammetry analysis revealed a one-electron quasireversible pair of waves assigned to the $\mathbf{V O}^{\mathbf{I V}} / \mathbf{V O}^{\mathbf{V}}$ electroactive species, the half-wave potentials near to $606 \mathrm{mV}$.

The catalyst VO(IV)L favored the formation of 2-cyclohexenone $(\mathbf{7 3 . 1 6 \%}$ and $\mathbf{6 3 . 5 6 \%})$ to the rest of the products in the presence of $\mathrm{O}_{2}$ and $\mathrm{H}_{2} \mathrm{O}_{2}$ oxidants. The activity of the oxovanadium complex in the oxidation of cyclohexene in the presence of $\mathrm{O} 2$ is much higher than in the presence of $\mathrm{H}_{2} \mathrm{O}_{2}\left(\mathbf{O}_{2}>\mathbf{H}_{2} \mathbf{O}_{2}\right)$.

\section{Supplementary Material}

CCDC-1516191 contains the supplementary crystallographic data for this paper. These data can be obtained free of charge via www.ccdc.cam.ac.uk/data_request/cif by e-mailing: data_request@ccdc.cam.ac.uk; or by contacting: The Cambridge Crystallographic Data Centre, 12 Union Road, Cambridge CB2 1EZ, UK; Fax: 44(0)1223-336033.

\section{Acknowledgement}

The Authors gratefully acknowledge the financial support from The Algerian Ministry of Higher Education and Scientific Research. They also acknowledge the help to access the NMR Facility and Microanalysis Service at GDS 3648 of the University of Strasbourg - CNRS - France. 


\section{Références}

[1] S. Chakraborty, C.R. Bhattacharjee, P. Mondal, S.K. Prasad, D.S. Rao, Dalton Trans. 44 (2015) 7477-7488.

[2] H.A. Rudbari, M.R. Farsani, S. Lanza, G. Bruno, B. Yadollahi, C R Chim. 18 (2015) 391398.

[3] M. Khorshidifard, H.A. Rudbari, B. Askari, M. Sahihi, M.R. Farsani, F. Jalilian, G. Bruno, Polyhedron. 95 (2015) 1-13.

[4] S. Park, V.K. Mathur, R.P. Planap, Polyhedron 17 (1998) 325-330.

[5] T. Nakamura, K. Niwa, M. Fujiwara, T. Matsushita, Chem. Lett. 10 (1999) 1067-1068.

[6] Y.K. Choi, W.S. Kim, K.I. Chung, M.W. Chung, H.P. Nam, Microchem. J. 65 (2000) 3-15.

[7] G. Grivani , V. Tahmasebi , A. D. Khalaji, Polyhedron. 68 (2014) 144-150.

[8] N. Chantarasiri, V. Ruangpornvisuti, N. Muangsin, H. Detsen, T. Mananunsap, C. Batiya, N. Chaichit, J. Mol. Struct. 701 (2004) 93-101.

[9] R. Ziessel, Coord. Chem. Rev. 195 (2001) 216-217.

[10] G Grivani , A. D. Khalaji , V. Tahmasebi , K. Gotoh , H. Ishida, Polyhedron 31 (2012) 265271

[11] R.S. Ray, B. Ghosh, A. Rana, M. Chatterjee, Int. J. Cancer .120 (2007) 13-23.

[12] J. Benítez, L. Becco, I. Correia, S.M. Leal, H. Guiset, J.C. Pessoa, J. Lorenzo, F. Aviles, P. Escobar, V. Moreno, B. Garat, D. Gambino. J. Inorg. Biochem. 105 (2011) 303-312.

[13] A. Adach, M. Daszkiewicz, M. Tyszka-Czochara, B. Barszcz, RSC Adv. 5 (2015) 8547085479

[14] D.C. Crans, J.J. Smee, E. Gaidamauskas, L. Yang, Chem. Rev. 104 (2004) 849-902.

[15] A. Butler, J.V. Walker, Chem. Rev. 93 (1993) 1937-1944.

[16] C.R. Cornman, E.P. Zovinka, M.H. Meixner, Inorg. Chem. 34 (1995) 5099-5100.

[17] R.R. Eady, Coord. Chem. Rev. 237 (2003) 23-30.

[18] D.C. Crans, J.J. Smee, E. Gaidamauskas, L.Q. Yang, Chem. Rev. 104 (2004) 849-902.

[19] J.H. McNeill, V.G. Yuen, H.R. Hoveyda, C. Orvig, J. Med. Chem. 35 (1992) 1489-1491.

[20] K.H. Thompson, J.H. McNeill, C. Orvig, Chem. Rev. 99 (1999) 2561-2571.

[21] A.J. Tasiopoulos, A.N. Troganis, A. Evangelou, C.P. Raptopoulou, A. Terzis, Y. Deligiannakis, T.A. Kabanos, Chem. Eur. J. 5 (1999) 910-921.

[22] O.J. D’Cruz, Y. Dong, F.M. Uckun, Biol. Reprod. 60 (1999) 435-444.

[23] Y. Dong, R.K. Narla, E. Sudbeck, F.M. Uckun, J. Inorg. Biochem. 78 (2000) 321-330.

[24] M.R. Maurya, A.K. Chandrakar, S. Chand, J. Mol. Catal. A: Chem. 274 (2007) 192-201.

[25] R. Ando, H. Ono, T. Yagyu, M. Maeda, Inorg. Chim. Acta 357 (2004) 817-823.

[26] S. Rayati, A. Ghaemi, N. Sadeghzadeh, Catal. Commun. 11 (2010) 792-796. 
[27] S. Rayati, M. Koliaei, F. Ashouri, S. Mohebbi, A. Wojtczak, A. Kozakiewicz, Appl. Catal. A: General 346 (2008) 65-71.

[28] M.R. Maurya, A.K. Chandrakar, S. Chand, J. Mol. Catal. A: Chem. 270 (2007) 225-235.

[29] M.R. Maurya, S. Sikarwar, P. Manikandan, Appl. Catal. A: General 315 (2006) 74-82.

[30] M.R. Maurya, A. Kumar, P. Manikandan, S. Chand, Appl. Catal. A: General 277 (2004) 4553.

[31] A. Mathavan, A. Ramdass, S. Rajagopal, Trans. Met. Chem. 40 (2015) 355-362.

[32] A. Mathavan, A. Ramdass, M. Ramachandran, S. Rajagopal, Int. J. Chem. Kinet. 47 (2015) 315-326.

[33] K.Mohammadi, M. Rastegari, Spectrochimica Acta Part A: Molecular and Biomolecular Spectroscopy, 97 (2012) 711-716.

[34] A.G.J. Ligtenbarg, R. Hage, B.L. Feringa, Coord. Chem. Rev. 237 (2003) 89-101.

[35] M.R. Maurya, M. Kumar, S.J.J. Titinchi, H.S. Abbo, S. Chand, Catal. Lett. 86 (2003)97-105.

[36] T.A. Alsalim, J.S. Hadi, O.N. Ali, H.S. Abbo, S.J.J. Titinchi, Chem. Central J. 7 (2013)3-11.

[37] T.A. Alsalim, J.S. Hadi, E.A. Al-Nasir, H.S. Abbo, S.J.J. Titinchi, Catal. Lett. 136(2010) 228233.

[38] H.S. Abbo, S.J.J. Titinchi, Top. Catal. 53 (2010) 1401-1410.

[39] K.A. JØrgensen, Transition-metal-catalyzed epoxidations, Chem. Rev. 89 (1989) $431-458$.

[40] G.Grivani, G.Bruno, H. A. Rudbari , A. D. Khalaji , P. Pourteimouri, Inorganic Chemistry Communications. 18 (2012) 15-20

[41] M.R. Maurya, S. Sikarwar, M. Kumar, Catal. Commun. 8 (2007) 2017-2024.

[42] M.R. Maurya, A. Kumar, M. Ebel, D. Rehder, Inorg. Chem. 45 (2006) 5924-5937.

[43] V.M. Dembitsky, Tetrahedron 59 (2003) 4701-4720.

[44] “M86-E01078 APEX2 User Manual”, Bruker AXS Inc., Madison, USA, 2006.

[45] G.M. Sheldrick, SHELXS-97 program for crystal structure determination, Acta Crystallogr. A46 (1990) 467-473.

[46] G. Sheldrick, SHELXL-97, Universität Göttingen, Göttingen, Germany, 1999.

[47] M. Dolaz, V. McKee, A. Gölcü, M. Tümer, Spectrochim. Acta Part A 71 (2009) 1648-1654.

[48] M. Asadi, Z. Asadi, N. Savaripoor, M. Dusek, V. Eigner, M. R. Shorkaei, M. Sedaghat, Spectrochim. Acta A. Mol. Biomol .Spectrosc. 136 (2015) 625-634

[49] S. Dekar, S. Bendia and K. Ouari, IUCrData (2017). 2, x170077

[50] W.J. Geary, Coord. Chem. Rev. 7 (1971) 81-122.

[51] B.T. Thaker, R.S. Barvalia ,Spectrochimi. Acta Part A. 84 (2011) 51- 61 
[52] M. Khorshidifard, H. A. Rudbari, B. Askari, M. Sahihi, M. R. Farsani, F. Jalilian, G. Bruno, Polyhedron. 95 (2015) 1-13.

[53] G. Grivania, S.H. Baghan, M. Vakili, A.D. Khalaji, V. Tahmasebi, V. Eignerd, M. Du_sek, J. Mol. Struct. 1082 (2015) 91-96.[54] M. Asadi, Z. Asadi, N. Savaripoor, M. Dusek, V. Eigner, M.R. Shorkaei, M. Sedaghat, Spectrochim. Acta Part A. 136 (2015)625- 634.

[55] G. Grivani, A. Ghavami, V. Eigner, M. Dusek, A.D. Khalaji, Chin. Chem. Lett. 26 (2015) 779784.

[56] K. Ouari, S. Bendia, J. Weiss, C. Bailly, Spectrochim. Acta A. Mol. Biomol. Spectrosc. 135 (2015) 624-631.

[57] A. N. Kursunlu, E. Guler, F. Sevgi, B. Ozkalp, J. Mol. Struct .1048 (2013) 476-481.

[58] M. Azam, Z. Hussain, I. Warad, S.I. Al-Resayes, M.S. Khan, M. Shakir, A. TrzesowskaKruszynskae, R. Kruszynski, Dalton Trans. 41 (2012) 10854 -10864.

[59] R. F.M. Elshaarawy, I. M. Eldeen, E. M. Hassan, J .Mol. Struct.1128 (2017) 162 -173.

[60] Y.L. Zhang, W.J. Ruan, X.J. Zhao, H.G. Wang, Z.A. Zhu, Polyhedron. 22 (2003) 1535-1545.

[61] R.B. Xiu, F.L. Mintz, X.Z. You, R.X. Wang, Q. Yue, Q.J. Meng, Y.J. Lu, D.V. Derveer, Polyhedron. 15 (1996) 4585-4591.

[62] I.V. Korendovych and E.V. Rybak-Akimova, Acta. Cryst. C, C60 (2004) 82-84.

[63] A. Ourari, K. Ouari, W. Moumeni and L. Sibous, Transition Metal Chemistry .31 (2006) 169175

[64] M. Khorshidifard, H. A. Rudbari, Z. Kazemi-Delikani, V. Mirkhani, R. Azadbakht, J. Mol. Struct. 1081 (2015) 494-505.

[65] N. Matsuoka, H. Kawamura, N. Yoshioka, Chem. Phys. Lett. 488 (2010) 32-37.

[66] G. Grivani, A.D. Khalaji, V. Tahmasebi, K. Gotoh, H. Ishida, Polyhedron. 31 (2012) 265-271.

[67] P. Plitt, H. Pritzkow, R. Kramer, Dalton Trans. (2004) 2314-2320.

[68] X. Wang, X.M. Zhang, H.X. Liu, Trans. Met. Chem. 19 (1994) 611-613.

[69] P. Plitt, H. Pritzkow, R. Kramer, Dalton Trans. (2004) 2314-2320.

[70] C. Lee, W. Yang, and R. G. Parr, Phys. Rev. B, 37,(1988) 785-789.

[71] A.D. Becke, J. Chem. Phys. 98 (1993) 5648- 5652.

[72] K. J. de Almeida, A. Cesar, Organometallics. 25 (2006) 3407-3416.

[73] R. O. Freire, G. B. Rocha, A. M. Simas, J Mol Model. 12 (2006) 373-389.

[74] V. Andrushchenko, D. Padula, E. Zhivotova, S. Yamamoto and P. Bour, Chirality. 26 (2014) 655-662.

[75] C. Sun, P. Zhao, M. Wei, Z. Chang, W. Li, Z. Anorg. Chem. 642 (2016) 372-376.

[76] T. C. Mikulas, M. Chen, Z. Fang, K. A. Peterson, L. Andrews, D. A. Dixon, J. Phys. Chem. A. 120 (2016) 793-804. 
[77] E. van Lenthe, A. Ehlers and E. J. Baerends, J. Chem. Phys. 110 (1999) 8943-8953.

[78] D. Hannachi, N. Ouddai, H. Chermette, Dalton Trans. 39 (2010) 3673-3680.

[79] A.D. Becke, J. Chem. Phys. 88 (1988) 2547-2553.

[80] D. Schlüns, K. Klahr, C. Mück-Lichtenfeld, L. Visscher, J. Neugebauer, Phys. Chem. Chem. Phys. 17 (2015) 14323-14341.

[81] E.J. Baerends, D. E. Ellis, P. Ros, Chem. Phys. 2 (1973) 41-51.

[82] C. F. Guerra, J. G. Snijders, G. te Velde, E. J. Baerends, Theor. Chem. Acc. 99 (1998) 391403.

[83] E.J. Baerends, T. Ziegler, A.J. Atkins, J. Autschbach, D. Bashford, A. Bérces, F.M. Bickelhaupt, C. Bo, P.M. Boerrigter, L. Cavallo, D.P. Chong, D.V. Chulhai, L. Deng, R.M. Dickson, J.M. Dieterich, D.E. Ellis, M. van Faassen, L. Fan, T.H. Fischer, C. Fonseca Guerra, M. Franchini, A. Ghysels, A. Giammona, S.J.A. van Gisbergen, A.W. Götz, J.A. Groeneveld, O.V. Gritsenko, M. Grüning, S. Gusarov, F.E. Harris, P. van den Hoek, C.R. Jacob, H. Jacobsen, L. Jensen, J.W. Kaminski, G. van Kessel, F. Kootstra, A. Kovalenko, M.V. Krykunov, E. van Lenthe, D.A. McCormack, A. Michalak, M. Mitoraj, S.M. Morton, J. Neugebauer, V.P. Nicu, L. Noodleman, V.P. Osinga, S. Patchkovskii, M. Pavanello, C.A. Peeples, P.H.T. Philipsen, D. Post, C.C. Pye, W. Ravenek, J.I. Rodríguez, P. Ros, R. Rüger, P.R.T. Schipper, H. van Schoot, G. Schreckenbach, J.S. Seldenthuis, M. Seth, J.G. Snijders, M. Solà, M. Swart, D. Swerhone, G. te Velde, P. Vernooijs, L. Versluis, L. Visscher, O. Visser, F. Wang, T.A. Wesolowski, E.M. van Wezenbeek, G. Wiesenekker, S.K. Wolff, T.K. Woo, A.L.Yakovlev, ADF2014.01, SCM, Theoretical Chemistry, Vrije Universiteit, Amsterdam, The Netherlands. <http://www.scm.com>.

[84] T. Koopmans, Physica. 1 (1934) 104-113.

[85] P. Perez, A. Aizman, R. Contreras, J. Phys. Chem. A. 106 (2002) 3964-3966.

[86] P. K. Chattaraj, B. Maiti, Int. J. Mol. Sci. 3 (2002) 338-359.

[87] K. R. S. Chandrakumar, S. Pal, Int. J. Mol. Sci. 3 (2002) 324-337.

[88] R. G. Parr, L. V. Szentpaly and S. Liu, J. Am. Chem. Soc.121 (1999) 1922-1924.

[89] L.R. Domingo, M.J. Aurell, P. Pérez, and R. Contreras, Tetrahedron. 58 (2002) 4417-4423.

[90] A. Anthonysamy, S. Balasubramanian, Inorg. Chem. Commun. 8 (2005) 908-911.

[91]A.H. Kianfar, M. Paliz, M. Roushani, M. Shamsipur, Spectrochim. Acta A. 82 (2011) 44- 48.

[92] A. Anthonysamy, S. Balasubramanian, Inorg. Chem. Commun. 8 (2005) 908-911.

[93] A. H. Kianfar, V. Sobhani, M. Dostani, M. Shamsipur, M. Roushani, Inorganica. Chim. Acta .365 (2011) 108-112.

[94] D. F. Back, G. M. de Oliveira, L. A. Fontana, A. Neves, B. A. Iglesias, T. P. Camargo, P. T. Campos, J. P. Vargas, Inorganica. Chim. Acta. 428 (2015) 163-169 
[95] V. B. Arion, V. C. Kravtsov, R. Goddard, E. Bill, J. I. Gradinaru, N. V. Gerbeleu, V. Levitschi, H.Vezin, Y. A. Simonov, J. Lipkowski, V. K. Bel'skii, Inorganica. Chim. Acta .317 (2001) 33-44. [96] M. Sarigul, P. Deveci, M. Kose, U. Arslan, H.T. Dagi, M.Kurtoglu, J. Mol. Struct. 1096 (2015) 64-73.

[97] M. Merzougui, K. Ouari, J. Weiss, J. Mol. Struct .1120(2016) 239-244.

[98] J. Losada, I. del Peso, L. Beyer, Inorg. Chim. Acta .321 (2001) 107-115.

[99] S. Gutierrez-Granados, F. Bedioui, J. Devynck, Electrochim. Acta .38 (1993) 1747-1751.

[100] M. R. Maurya, A. K. Chandrakar, S. Chand , J. Mol. Catal A. Chem. 270 (2007) 225-235.

[101] R.Noyori, M. Aokib and K. Sato, CHEM. COMMUN. (2003) 1977-1986.

[102] G. Grivani, G. Bruno, H. A. Rudbari, A. D. Khalaji, P. Pourteimouri, Inorg. Chem. Commun. 18 (2012) 15-20. 